\title{
Biology of Streptococcus mutans-Derived Glucosyltransferases: Role in Extracellular Matrix Formation of Cariogenic Biofilms
}

\author{
W.H. Bowen ${ }^{\mathrm{a}, \mathrm{b}} \quad$ H. Koo ${ }^{\mathrm{a}, \mathrm{b}, \mathrm{c}}$ \\ ${ }^{a}$ Center for Oral Biology, ${ }^{b}$ Department of Microbiology and Immunology and ' Eastman Department of Dentistry, \\ University of Rochester, Rochester, N.Y., USA
}

\section{Key Words}

Biofilms - Dental caries $\cdot$ Extracellular matrix .

Glucosyltransferases $\cdot$ Polysaccharides $\cdot$ Streptococcus mutans

\begin{abstract}
The importance of Streptococcus mutans in the etiology and pathogenesis of dental caries is certainly controversial, in part because excessive attention is paid to the numbers of S. mutans and acid production while the matrix within dental plaque has been neglected. S. mutans does not always dominate within plaque; many organisms are equally acidogenic and aciduric. It is also recognized that glucosyltransferases from S. mutans (Gtfs) play critical roles in the development of virulent dental plaque. Gtfs adsorb to enamel synthesizing glucans in situ, providing sites for avid colonization by microorganisms and an insoluble matrix for plaque. Gtfs also adsorb to surfaces of other oral microorganisms converting them to glucan producers. S. mutans expresses 3 genetically distinct Gtfs; each appears to play a different but overlapping role in the formation of virulent plaque. GtfC is adsorbed to enamel within pellicle whereas GtfB binds avidly to bacteria promoting tight cell clustering, and enhancing cohesion of plaque. GtfD forms a soluble, readily metabolizable polysaccharide and acts as a primer for GtfB. The behavior of soluble Gtfs does not mirror that observed with sur-
\end{abstract}

face-adsorbed enzymes. Furthermore, the structure of polysaccharide matrix changes over time as a result of the action of mutanases and dextranases within plaque. Gtfs at distinct loci offer chemotherapeutic targets to prevent caries. Nevertheless, agents that inhibit Gtfs in solution frequently have a reduced or no effect on adsorbed enzymes. Clearly, conformational changes and reactions of Gtfs on surfaces are complex and modulate the pathogenesis of dental caries in situ, deserving further investigation.

Copyright $\odot 2011$ S. Karger AG, Basel

Put simply, there is no biofilm without an extracellular polysaccharide (EPS) matrix [Flemming and Wingender, 2010]. The word 'plaque' in a dental context was probably first used by Black [1886] when he described the collective accumulation of microorganisms on early carious lesions. Dental plaque, which has endured various definitions, is clearly a biofilm, i.e. a group of microorganisms embedded in a matrix attached to the tooth surface. All biofilms have at least one property in common, i.e. the presence of a bacterially derived matrix [Flemming and Wingender, 2010]. The structure, e.g. branching of EPS and, to a lesser extent, the composition (e.g. proportions of soluble and insoluble polymers) of the matrix may be as variable as the microbial constituents and is influenced by local environmental conditions and even changes with

\section{KARGER}

(C) 2011 S. Karger AG, Basel

Fax +4161306 1234

E-Mail karger@karger.ch

www.karger.com
Accessible online at:

www.karger.com/cre
William H. Bowen, BDS, PhD

University of Rochester, Center for Oral Biology

601 Elmwood Avenue, Box 611

Rochester, NY 14642 (USA)

Tel. +1 585275 0772, E-Mail William_Bowen@urmc.rochester.edu 
time [Branda et al., 2005]. Clearly the structure of the polysaccharide matrix can play a critical role affecting the virulence of plaque by influencing the physical and biochemical properties of biofilm. It may enhance adherence of microorganisms, promote coherence, act as reserve source of energy, protect microorganisms from inimical influences, affect diffusion of substances into and out of biofilm, and help to concentrate metal ions and other physiological nutrients within a microenvironment [Tatevossian, 1990; Wilson and Ashley, 1990; Hayacibara et al., 2004; Paes Leme et al., 2006; Flemming and Wingender, 2010; Koo et al., 2010b].

\section{Composition of Dental Plaque}

The broad composition of the biofilm known as dental plaque has been explored. Glucan (see below) comprises $10-20 \%$ dry weight of dental plaque and fructan approximately $1-2 \%$; clearly these proportions will vary depending in part at least on the duration since the last intake of food [Critchley et al., 1967; Gibbons, 1968; Wood, 1969; Mayhall and Butler, 1976; Emilson et al., 1984]. Dental plaque also contains approximately $40 \%$ dry weight protein (mostly derived from bacteria and saliva), variable amounts of lipid, Ca, P, Mg and F compared with surrounding saliva [Hotz et al., 1972; Cole and Bowen, 1975; Paes Leme et al., 2006; Pessan et al., 2008]. Dental plaque in situ harbors approximately $80 \%$ water [Wilson and Ashley, 1990].

Electron histochemistry and transmission electron microscopy of dental plaque reveals microorganisms embedded in a matrix of polysaccharide [McDougall, 1963; Reese and Guggenheim, 2007], which appears to increase following exposure to sucrose [Saxton and Kolendo, 1967; Critchley et al., 1968]. All the available evidence shows clearly that the primary sources of EPS in dental plaque are products from the interaction of glucosyltransferases (Gtfs) and fructosyltransferases with sucrose and starch hydrolysates [Vacca-Smith et al., 1996a].

\section{Role of Gtfs in Dental Plaque Formation}

\section{Acquired Enamel Pellicle and Gtfs}

The earliest evidence of plaque formation is the appearance of a pellicle on the tooth surface [Leach and Saxton, 1966; Hay, 1967; Siqueira et al., 2007]. This material is repeatedly referred to as salivary pellicle even though it is clear that the pellicle harbors significant amounts of nonmammalian constituents [Eggen and Rölla, 1983; Rölla et al., 1983a; Vacca-Smith and Bowen, 1998; Hannig et al., 2008a] which influence the subsequent development of plaque. The saliva-derived constituents are selectively adsorbed to the surface, and include but are not limited to proline-rich proteins, amylase, lysozyme, histatins, peroxidase, statherin and mucin 2 [Mayhall and Butler, 1976; Siqueira et al., 2007]. Some of these materials undergo conformational change when adsorbed to tooth surfaces and may then provide specific binding sites for some microorganisms [Hay et al., 1971; Gibbons et al., 1990].

The presence of bacterial cellular material in pellicle was reported by Armstrong [1967], but it remained for Rölla et al. [1983a] and Scheie et al. [1987] to identify the presence of soluble bacterial products in pellicle using immunological techniques. They identified fructosyltransferase, Gtf and lipoteichoic acid in pellicle formed in vitro and in vivo from whole saliva. These observations were subsequently confirmed and extended by VaccaSmith et al. [1996b] in pellicles formed on apatitic surface in situ. The Gtfs present in pellicle were shown by Schilling and Bowen [1988] to be active and capable of synthesizing glucan in situ from sucrose and provided binding sites for many oral microorganisms, including mutans streptococci. Gtfs present in whole saliva are incorporated into pellicle and form part of its structure; furthermore, Gtf added to ductal saliva (Gtf-free) is also adsorbed in active form onto hydroxyapatite (HA) surfaces [Schilling and Bowen, 1988]. Remarkably, Gtf incorporated into pellicle adsorbed to an HA surface displayed 3-4 times enhanced activity compared with similar amounts of enzyme in solution [Schilling et al., 1989; Venkitaraman et al., 1995; Vacca-Smith et al., 1996b].

Furthermore, it was observed that the enzymes when insolubilized remained highly active over a wide range of $\mathrm{pH}$ values [Schilling and Bowen, 1988; Venkitaraman et al., 1995; Vacca-Smith et al., 1996b]. It is clear that the presence of active Gtf within dental pellicle facilitates the formation of glucan in situ, thereby providing distinct binding sites for oral microorganisms. It can therefore be hypothesized that Gtfs from S. mutans influence the microbial colonization of tooth surfaces.

\section{Gtf Sources}

Gtf can be readily assayed in whole saliva from many persons, particularly those who are caries active [Scheie and Rölla, 1986; Scheie et al., 1987; Vacca-Smith et al., 2007]. Gtfs are remarkably stable even in whole saliva; measured amounts of purified Gtf enzymes added to 
whole saliva remained completely active for up to $4 \mathrm{~h}$ at least [Vacca-Smith et al., 1996b]. Several groups of oral microorganisms produce Gtfs; these include Streptococcus sanguinis, Streptococcus mutans, Streptococcus sobrinus, Actinomyces spp., Streptococcus salivarius and Lactobacillus spp. [Newbrun, 1974]. The review presented here will focus on the Gtfs from S. mutans.

$S$. mutans produces at least 3 genetically separate $\mathrm{Gtfs}$, each of which synthesizes a structurally distinct glucan from sucrose. Details of the structural and functional organization of Gtfs are found elsewhere [for reviews, see Monchois et al., 1999; van Hijum et al., 2006]. GtfB (formally known as GtfI) synthesizes primarily insoluble glucan rich in $\alpha$-1,3-linkages, GtfC (GtfSI) produces a mixture of soluble (with mostly $\alpha$-1,6-linkages) and insoluble glucans, and GtfD (GtfS) forms predominantly soluble glucans [Aoki et al., 1986; Hanada and Kuramitsu, 1988, 1989]. Superficially, it may appear bizarre that microorganisms produce 3 distinct enzymes to act on the same substrate to form polysaccharides. We hypothesize with supporting data that each one plays a distinct role in the formation of dental plaque and, as a result, $S$. mutans has a far greater influence on the formation and composition of plaque than its population would appear to warrant.

\section{Gtfs in the Pellicle and on Bacterial Surfaces}

Gtf adsorbs to experimental pellicles formed on apatitic surfaces in situ with extraordinary rapidity; active $\mathrm{Gtf}$ is detected on HA disks within 1 min of placing them in the mouth. Prerinsing with sucrose enhances the amount of enzyme detected, possibly because Gtf will adhere to glucan formed in situ [Scheie et al., 1987; VaccaSmith and Bowen, 2000]. In vitro, Gtf binds poorly to uncoated HA and loses much of its activity [Schilling and Bowen, 1988; Vacca-Smith and Bowen, 1998]; in contrast, Gtf adsorbs to saliva-coated HA (sHA) disks avidly with enhanced activity [Venkitaraman et al., 1995; Steinberg et al., 1996].

Results from early studies, before separate gene products were available, provided little information on which Gtf is present in pellicle [Schilling and Bowen, 1988]. As a result of cloning and gene deletion, the Gtf enzymes have been prepared separately and at a high level of purity which has led to rapid advances in the field [Hanada and Kuramitsu, 1988; Fukushima et al., 1992]. Although all 3 enzymes can bind to $\mathrm{sHA}$, their affinity differs greatly [Vacca-Smith and Bowen, 1998]. GtfC has the greatest affinity for sHA, and in addition, based on Scatchard plots, GtfC displayed significantly more binding sites than did either GtfB or GtfD. Although GtfD binds to sHA, it displays relatively few binding sites. It is also noteworthy that the $\mathrm{K}_{\mathrm{m}}$ values for the 3 enzymes are lower by two- to eightfold following adsorption to sHA, an observation consistent with the reported enhanced activity of the insolubilized enzymes compared with the same enzymes in solution [Kuramitsu and Ingersoll, 1978; Venkitaraman et al., 1995; Steinberg et al., 1996]. The activity of GtfB is enhanced greatly by the inclusion of primer dextran in the test system [Koga et al., 1988; Venkitaraman et al., 1995; Vacca-Smith et al., 1996a; Kopec et al., 1997]. In contrast, Gtf detected in pellicle is not enhanced by primer dextran. Furthermore, the activity of GtfC is enhanced substantially when it is adsorbed to sHA; enhancement is not observed with GtfB adsorbed to sHA. The binding of GtfB to sHA in the presence of ductal parotid saliva supplemented with GtfC and GtfD was reduced when compared with its binding to sHA in the presence of parotid saliva alone. In contrast, the binding of GtfC or GtfD enzymes to sHA was unaffected by addition of other Gtfs [Vacca-Smith and Bowen, 2000]. We conclude therefore that the Gtf in pellicle has properties that are certainly consistent with it being GtfC [VaccaSmith et al., 1996b]. Data from in situ and in vitro studies suggest strongly that Gtf detected in pellicle is primarily GtfC from S. mutans [Venkitaraman et al., 1995; VaccaSmith and Bowen, 2000].

Gtfs also have the capacity to bind to many oral bacteria [McCabe and Donkersloot, 1977; Hamada et al., 1978; Vacca-Smith and Bowen, 1998], even those that do not synthesize Gtfs. We have observed that GtfB binds with greater avidity to oral microorganisms, e.g. Actinomyces viscosus, Lactobacillus casei and S. mutans, than do the other Gtfs from S. mutans and that the binding to bacteria occurs even in the presence of ductal saliva. Furthermore, the enzyme retains its activity when adsorbed to bacteria, thereby converting non-Gtf producers into de facto glucan formers [Vacca-Smith and Bowen, 1998].

The simultaneous synthesis of glucans by surface-adsorbed GtfB and GtfC is essential for the establishment of a matrix that enhances the coherence of bacterial cells and adherence to apatitic surfaces, allowing the formation of highly organized and dense cell clusters known as microcolonies [Tamesada et al., 2004; Koo et al., 2010b; Xiao and Koo, 2010]. These phenomena may well explain the observations on histochemical preparations of even early plaque that reveal microorganisms embedded in a polysaccharide matrix [Critchley et al., 1968; Venkitaraman et al., 1995; Reese and Guggenheim, 2007]. 


\section{Adhesion of Gtfs to Surfaces}

The precise mechanisms involved in the binding of Gtfs to sHA and bacterial surfaces remain to be elucidated. The same type of basic structure is found in all Gtfs [Russell et al., 1988; Russell, 1994; Vacca-Smith and Bowen, 1998]. Each enzyme has at the amino terminus a signal peptide comprised of approximately 38 amino acids; adjacent to this peptide is a very variable domain constituted by about 200 amino acids characteristic for each of the enzymes [van Hijum et al., 2006]. The amino acid composition and structure of the Gtfs may clarify the distinct binding capacities of each enzyme.

A series of repeat motifs of amino acids that varies for each enzyme is found at the $\mathrm{C}$ terminus. The $\mathrm{C}$ termini found in GtfB and GtfC differ in composition, which may explain in part at least the preferential adsorption of GtfC enzyme to sHA and of GtfB enzyme to bacterial surfaces. The GtfB and GtfD are comparable in structure and both are hydrophilic [Shiroza et al., 1987; Honda et al., 1990]. GtfC is also hydrophilic; however, in contrast to the GtfB and GtfD enzymes, it harbors a hydrophobic domain within the direct repeat units in the $\mathrm{C}$ terminus [Ueda et al., 1988]. The presence of small hydrophobic domains in GtfC may be associated with pellicle-binding activity of this enzyme, possibly through interactions with specific salivary macromolecules found in the pellicle, such as lysozyme and $\alpha$-amylase [Vacca-Smith et al., 1996a; Vacca-Smith and Bowen, 1998]. Conversely, the presence of specific carboxyl-terminal repeat units of $\mathrm{GtfB}$ has a major role in the binding of the enzyme to the cell surface of oral streptococci [Kato and Kuramitsu, 1991].

It is noteworthy [Vickerman et al., 1996, 2003] that the ability of Gtf enzymes from S. gordonii to bind to biotindextran was dramatically reduced following deletion of the C-terminal hydrophilic residue. Using a series of deletion derivatives for the $\mathrm{C}$ terminus, it has been shown that direct repeat units constitute part of the minimum domain required for the lectin type glucan binding by S. mutans GtfD [Mooser and Wong, 1988; Lis et al., 1995]. The C-terminal glucan-binding domain of GtfD contains five 65-amino-acid direct repeat units. The removal of the single direct repeat unit significantly reduced the ability of the protein to bind glucans [Lis et al., 1995] and may be necessary for enzyme catalytic activity [van $\mathrm{Hi}$ jum et al., 2006]. However, the precise role of the glucanbinding domain on the conformation-function relationship of Gtf enzymes, including the presumed $(\beta / \alpha) 8$ barrel structure in the catalytic domain, remains largely unknown [van Hijum et al., 2006]. Nevertheless, the ter- tiary structure of the glucan-binding domain (presumably containing a high percentage of $\beta$-sheet) may be essential for the lectin type glucan binding by GtfD [Mooser and Wong, 1988; Banas and Vickerman, 2003; van Hijum et al., 2006].

In addition, Gtfs also bind to other components of the salivary pellicle such as salivary peroxidase, amylase and lysozyme [Korpela et al., 2002; Hannig et al., 2005; Kho et al., 2005]. Available data shows clearly that Gtfs interact with salivary amylase in pellicle [Vacca-Smith et al., 1996a] inhibiting activity and blocking adsorption of salivary amylase to HA [Hannig et al., 2005]. Lactoperoxidase in the absence of substrates, which is structurally and enzymatically similar to salivary peroxidase, inhibits all $3 \mathrm{Gtf}$ enzymes in solution or adsorbed to sHA beads [Korpela et al., 2002]. The presence of lysozyme reduced the activity of GtfB in solution and on a surface but was without apparent effect on the structure of glucan formed [Kho et al., 2005]. The interactions of Gtf with peroxidase and lysozyme in salivary pellicle could result in decreased colonization of tooth surfaces as a consequence of depressed glucan production.

It is also noteworthy that many oral microorganisms, including S. mutans, adsorb lysozyme, amylase and other salivary proteins [Douglas, 1983; Douglas and Russell, 1984; Ambatipudi et al., 2010], which may influence the binding of GtfB on the bacterial cell surface. The simultaneous binding of GtfB and salivary amylase and their interactions create the opportunity to synthesize complex insoluble glucans directly on the bacterial surface [Vacca-Smith et al., 1996a; Chaudhuri et al., 2007].

\section{Gtf Activity and Glucan Structure}

The attention to oral biofilms has been enhanced greatly in recent years largely because it is recognized that microorganisms behave differently in biofilms compared with that in the planktonic state [Marsh and Bradshaw, 1995; Hall-Stoodley et al., 2004]. Enzymes too may behave differently when adsorbed to a surface compared with solubilized enzymes [Fears and Latour, 2009]. The adsorption of Gtf to sHA results in substantial enhancement of activity compared with activity of the same enzyme in solutions [Schilling and Bowen, 1988]. In contrast to what occurs on sHA, Gtf adsorbs comparatively poorly to uncoated HA and loses some activity. Even more remarkable is the difference in structure of glucans formed by GtfB and GtfC when adsorbed to sHA compared with the product formed when the same enzyme is in solution. Based on susceptibility to dextranase and mutanase, products of digestion and structural analyses, 
there is a dramatic increase in the number of $\alpha$-1,3-linkages and a higher percentage of 3-linked branch points (e.g. 2,3-, 3,4-, 3,6- and 3,4,6-linked glucose) in the surface-formed glucan compared with that formed by the same enzymes in solution.

The presence of starch hydrolysates, associated with gradual digestion of starch by salivary $\alpha$-amylase (free in solution, adsorbed onto apatite and/or microbial surfaces), also influences the formation and structure of glucan by GtfB [Vacca-Smith et al., 1996a]. The hydrolysates, which include a range of high-molecular-weight oligomers $(>1 \mathrm{kDa})$, maltotriose and maltose/isomaltose [Klein et al., 2010], can serve as acceptor sites for polymer formation, constituting an integral part of the polymer molecule [Fukui and Moriyama, 1983; Koga et al., 1988; Fu and Robyt, 1991]. Furthermore, it appears that these carbohydrates can serve as substrate for the addition of branches to glucan even in the absence of sucrose [McCabe and Hamelik, 1983]. The combination of starch hydrolysates and sucrose with surface-adsorbed GtfB results as expected in enhanced formation of predominantly insoluble glucan and an increase in the number of $\alpha-1,4-$ and $\alpha-1,3$ - linkages with 3,4-linked glucose as the major branch point [Kopec et al., 1997]. Inclusion of starch hydrolysates with sucrose is without effect on the structure of product formed by GtfC and GtfD. It is noteworthy that parts of Gtf molecules have substantial sequence similarity with members of the $\alpha$-amylase family [van Hijum et al., 2006]. The significance of Gtf similarity is underlined by $\mathrm{Gtf} / \alpha$-amylase residues conserved in all but one $\alpha$-amylase invariant residue [Devulappalle et al., 1997]. Moreover, the presence of amylase increased both the sucrase and transferase component activities of GtfB [Chaudhuri et al., 2007].

The product from the starch-sucrose substrate resembles in some measure the structure reported for plaque polysaccharide [Hotz et al., 1972; Birked and Rosell, 1975]. Furthermore it provides distinct binding sites for some oral microorganisms. For example, Actinomyces spp. and $S$. mutans bind in larger numbers to glucan formed on sHA surface in the presence of starch hydrolysates as compared to glucan formed in the absence of starch [Vacca-Smith et al., 1996a]. Sucrose is frequently consumed with starch, and this combination could clearly influence the composition, structure and physical properties of plaque matrix (more details later).

Clearly, the glucans formed on surfaces are highly insoluble, and furthermore provide distinct binding sites for microorganisms [Kopec et al., 1997] and affect the 3-dimensional structure of the matrix [Koo et al., 2010b].
Whether similar phenomena occur with glucans formed on bacterial surfaces remains to be determined.

\section{Gtf-Glucan-Mediated Bacterial Adherence}

The adherence of microorganisms to the tooth surface is critical in the formation of dental plaque, and understandably much attention has been focused on microbial binding to uncoated tooth surfaces, HA, polystyrene (plastic) or glass [Morris and McBride, 1984; Gibbons and Hay, 1989; Schilling and Bowen, 1992]. Non-pellicle-covered teeth rarely if ever occur in vivo. Salivary glycoproteins and bacterial products can be detected on HA disks within 30 s of being placed in the mouth [Hay et al., 1971; Vacca-Smith and Bowen, 2000; Hannig et al., 2008a]. Saliva-coated disks prepared in situ assayed directly for enzyme activity revealed that fructosyltransferase activity increased up to $1 \mathrm{~min}$ of exposure and decreased when kept in the mouth for longer periods. Gtf activity on the disks in contrast increased the longer the disks were kept in the mouth [Scheie et al., 1987; Vacca-Smith and Bowen, 2000]. Many oral microorganisms do not adhere in large numbers to uncovered HA [Schilling and Bowen, 1992] and even fewer adhere to sHA [Schilling and Bowen, 1988; Schilling et al., 1989; Venkitaraman et al., 1995; Vacca-Smith and Bowen, 1998] even though considerable selectivity is apparent, and novel binding sites in salivary glycoproteins are revealed (cryptotopes) as a result of adsorption to HA surface [Gibbons et al., 1990]. These observations on adherence are in marked contrast to what occurs when glucan is formed in situ on the surface of HA. With glucan synthesized from surface Gtfs (particularly GtfB and GtfC but not GtfD), there is a threefold increase in the number of $S$. mutans adhering to the glucan-coated surface compared with the number adhering to an uncoated HA or sHA surface [Kuramitsu, 1974; Schilling and Bowen, 1992; Venkitaraman et al., 1995].

The binding of $S$. mutans to glucans formed in situ is mediated by the presence of cell-associated Gtf enzymes and non-Gtf glucan-binding proteins (Gbps). At least 4 Gbps have been identified in S. mutans, GbpA, GbpB, GbpC and GbpD [Guggenheim, 1970; Russell, 1979; Banas and Vickerman, 2003]. GbpA and GbpD contain carboxyl-terminal repeats similar to those found in the glucan-binding domain of Gtf enzymes. The glucanbinding domain of $\mathrm{GbpC}$ has not been identified although it shares homology with the AgI/II family of proteins; GbpB is similar to peptidoglycan hydrolase [Banas and Vickerman, 2003]. Among them, GbpC (and possibly $\mathrm{GbpB}$ ) is cell wall bound and may function as cell surface glucan receptors in S. mutans [Banas and Vickerman, 
2003]. Each of the Gbps appears to have a role in sucrosedependent adhesion and biofilm formation by $S$. mutans, although loss of cell-surface-anchored GbpC was the most disruptive [Lynch et al., 2007].

The inclusion of dextran ( $\alpha$-1,6-linked glucan; molecular weight 9,000) in the model system effectively blocks or reduces adherence of microorganisms to glucan-coated apatitic surface. Furthermore, treating the in situ formed glucan with dextranase [Schilling et al., 1989; Venkitaraman et al., 1995] prevented or reduced bacterial adherence whereas mutanase treatment $(\alpha-1-3)$ was without effect. These observations suggest strongly that presence of $\alpha$-1,6-linkages in GtfB- and GtfC-derived glucans is conferring a specific structure or conformation that provides at least 1 binding site.

Results from using atomic force microscopy demonstrate that attachment of $S$. mutans to tooth surfaces was largely mediated by glucan production and that attachment strengthens with time [Cross et al., 2007]. Evidence is lacking that ionic interactions play a role in the binding of S. mutans to glucan [Cross et al., 2007], especially considering that glucan formed in vitro is uncharged. Furthermore, it is apparent that glucan synthesized in situ by Gtf in pellicle provides enhanced binding for several oral microorganisms. Thus, it appears that a glucan surface on HA (mostly produced by GtfC) provided distinct binding sites for oral microorganisms that do not bind readily to HA or sHA. Concomitantly, glucan formed by Gtf adsorbed to the surface of cells (primarily GtfB) provides an opportunity for aggregation and accumulation of cells and structural support for development of microcolonies (fig. 1) at the same time increasing the bulk of plaque. It is apparent that the formation of cell clusters and microcolonies tightly adherent on the surface of HA is a result of interplay between GtfB and GtfC enzymes and their glucan products at different loci [Koo et al., 2010b]. The presence of highly adherent and insoluble glucans in situ increases mechanical stability by binding the bacterial cells together and to the apatite surface (fig. 1) allowing them to persist on tooth enamel in high levels for a prolonged period. These polymers, in addition to interactions with specific Gbps expressed on S. mutans (and other oral microorganisms) are critical in maintaining the 3-dimensional structure of microcolonies over time (fig. 1), thereby modulating the development of cariogenic biofilms [Lynch et al., 2007; Koo et al., 2010b; Xiao and Koo, 2010]. Based on these observations, we have revised and updated the glucan-mediated bacterial adherence model initially proposed by Rölla et al. [1983b] as shown in figure 2.

\section{Exopolysaccharide Matrix and Cariogenic Plaque Development}

The precise role(s) of EPS in the pathogenesis of dental caries is in some measure controversial. Nevertheless, there is considerable agreement on many aspects [Paes Leme et al., 2006]. Glucan formed on the tooth surface synthesized by Gtf incorporated into the pellicle from sucrose can provide enhanced binding sites for a number of oral microorganisms, especially $S$. mutans. In turn, microorganisms that synthesize glucans, or adsorb Gtf and become de facto glucan producers, form highly stable and persistent microcolonies. The exopolymers produced in situ provide a coherent, adherent and mechanically stable matrix, and offer a continuum of a diverse range of binding sites; the structure of glucan is altered over time by the presence of mutanases and dextranases [Guggenheim and Burckhardt, 1974; Walker et al., 1981; Hayacibara et al., 2004]. In addition, Gtfs may bind to the glucan already formed within dental plaque [Tamasada et al., 2004]. Glucan adds to the bulk of plaque thereby leading to a dense concentration of microorganisms on cloistered sites of tooth surfaces protected from inimical influences [Thurnheer et al., 2003; Kreth et al., 2008; Xiao and Koo, 2010]. In addition, soluble glucans may be readily digested and used as a reserve source of energy and contribute in part at least to the low $\mathrm{pH}$ values observed in cariogenic plaque [as reviewed in Paes Leme et al., 2006]. It is also noteworthy that elevated amounts of insoluble glucans in dental plaque significantly reduced the inorganic concentration in the matrix, particularly $\mathrm{Ca}, \mathrm{P}$ and $\mathrm{F}$ [Cury et al., 2000; Paes Leme et al., 2006, 2008]. Plaque should not be viewed as a homogeneous accumulation of microorganisms within a matrix but as a collection of highly organized microenvironments which can display distinct structures, compositions and diverse $\mathrm{pH}$ values (ranging from as low as $\mathrm{pH} 4$ at the tooth-biofilm interface to as high as $\mathrm{pH} 6.5$ at the biofilm-fluid phase) [Xiao et al., unpubl. data].

The physical role that glucan in plaque plays in cariogenesis is subject to diverse opinions. It is postulated that glucan limits diffusion of charged ions into and out of plaque whereas uncharged substances such as sucrose may diffuse readily [Melvaer et al., 1972, 1974; Melsen et al., 1979]. Available evidence suggests that the EPS from S. mutans and possibly additional oral microorganisms may be charged possibly by the incorporation of lipoteichoic acid [Melvaer et al., 1972, 1974; Melsen et al., 1979; Kuramitsu et al., 1980; Rölla et al., 1980; Vickerman and Jones, 1992]. In addition, Rölla et al. [1980] have observed elevated levels of lipoteichoic acid in sucrose-induced dental plaque in vivo. Based on extensive in vitro model- 

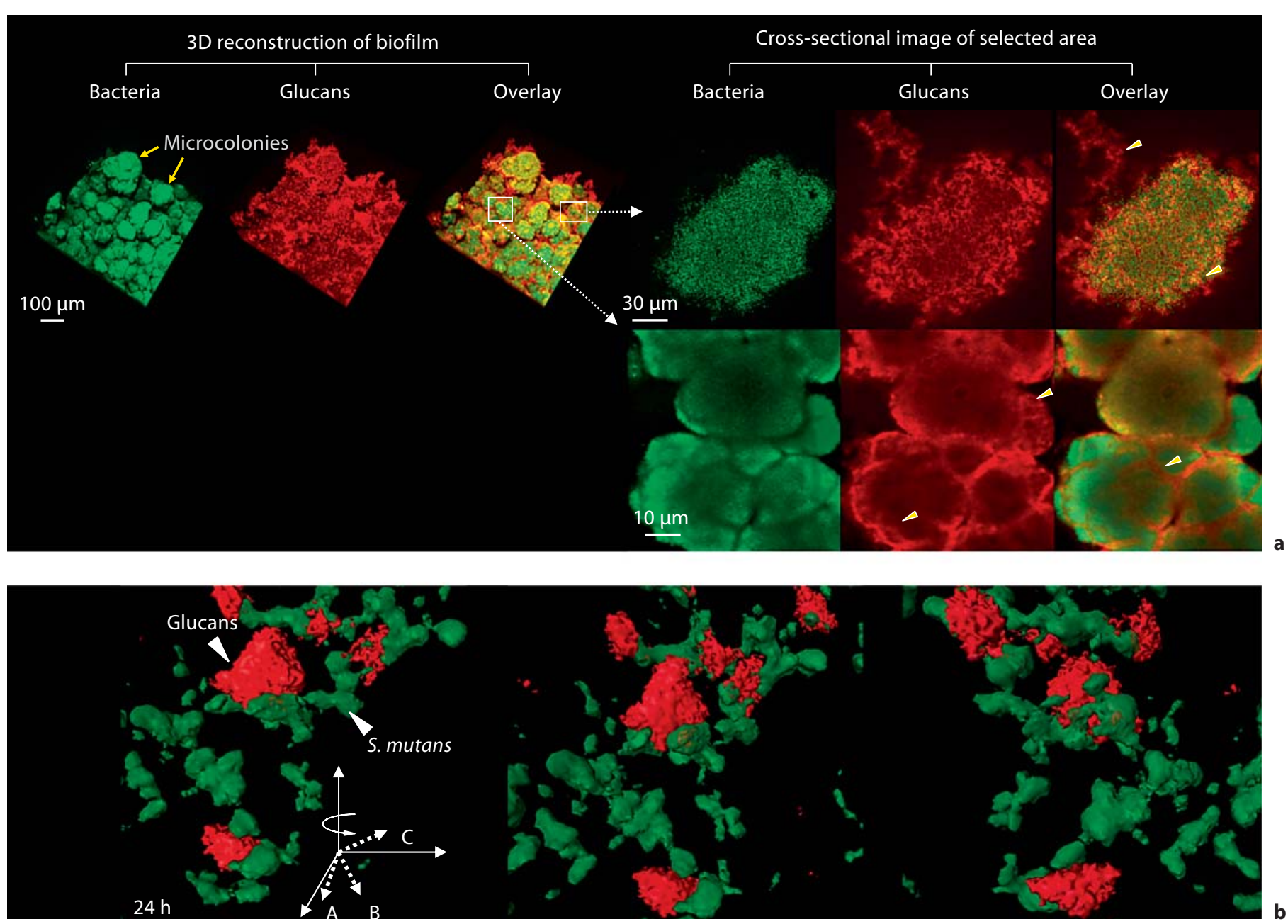

Fig. 1. a Representative confocal images of bacterial cells (in green) and glucans (in red) within biofilms formed by $S$. mutans US 159 on tooth enamel surface in the presence of $1 \%$ (wt/vol) sucrose. Arrowheads indicate structural organization of glucans within microcolonies. b Close-up view of 3-dimensional structural relationship between glucans and $S$. mutans cells.

ing, Dibdin and Shellis [1988] suggest that polysaccharides within plaque have little or no influence on diffusion and that spaces within the matrix of plaque provide 'storage' of acids and microbial products thereby providing effective maintenance of an elevated concentration of acid in contact with the tooth surface; they further suggest that this property alone may account for the virulence of the acid attack from dental plaque without invoking diffusion limitations. These observations are supported in part by Hata and Mayanagi [2003], who noted that EPS had little effect on acid diffusion in artificial plaque. In contrast, Tatevossian [1990] and others [Wilson and Ashley, 1990] note that concentrations of solutes in plaque fluid differ markedly from those observed in saliva, an observation which suggests that there is some restriction between the interior of dental plaque and its external environment. Furthermore, it appears that diffusion rates measured by different methods are widely diverse. Tatevossian [1990] further notes: 'We have much to learn about the fluid environment of the teeth and about dynamic changes in plaque fluid composition and properties during perturbations.' Polysaccharide within dental plaque is not evenly distributed, and its density is enhanced at the tooth interface [Saxton and Kolendo, 1967; Reese and Guggenheim, 2007]. The presence of EPS-rich matrix and microcolonies appears to create a myriad of microenvironments displaying a distinct range of in situ $\mathrm{pH}$ values [Xiao et al., unpubl. data]. 


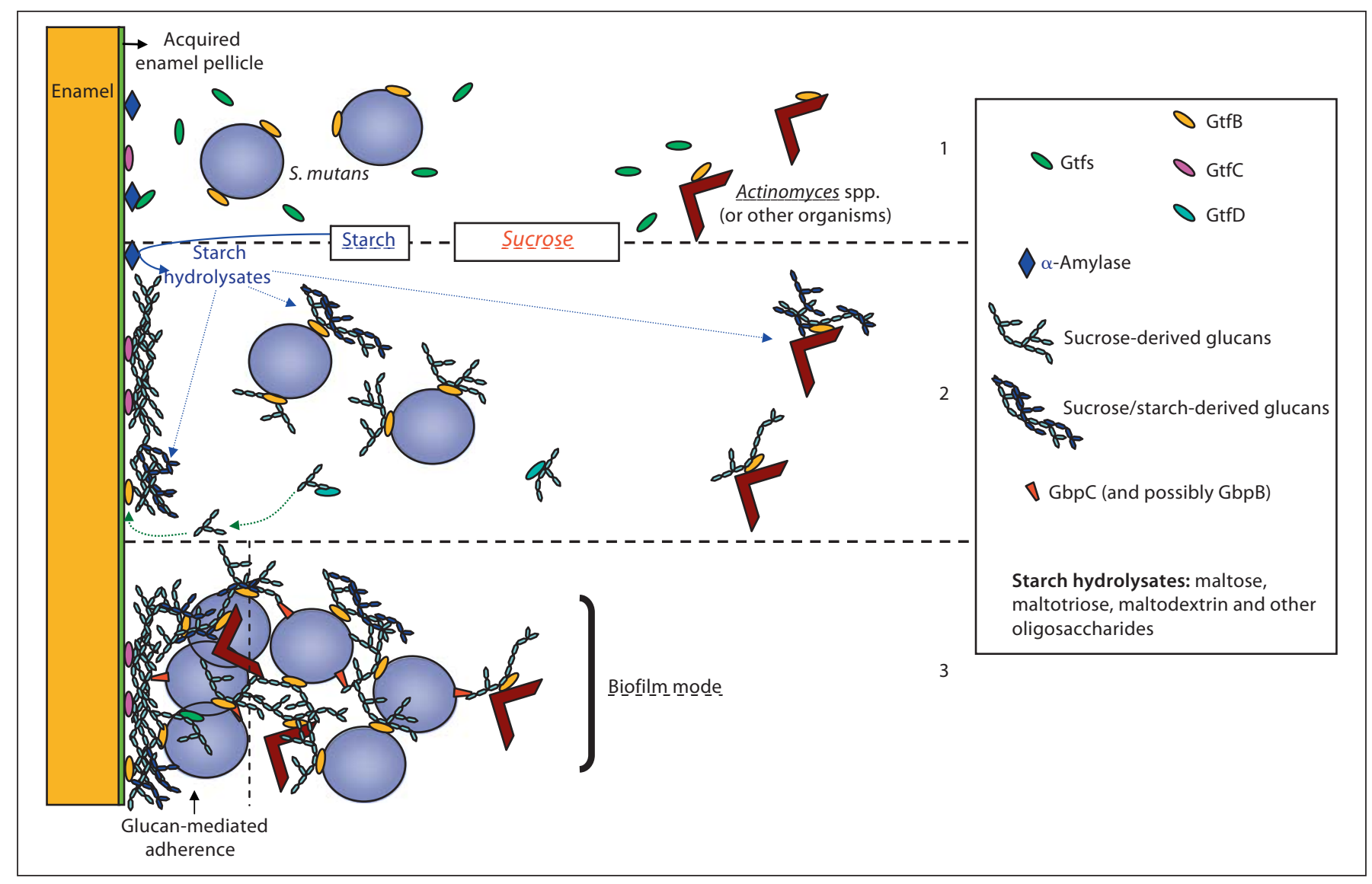

Fig. 2. Revised model of Gtf-glucan-mediated bacterial adherence and cariogenic biofilm development. Originally proposed by Rölla et al. [1983b]. (1) The Gtfs secreted by S. mutans are incorporated into pellicle (particularly GtfC) and adsorb on bacterial surfaces (mainly GtfB), including microorganisms that do not produce Gtfs (e.g. Actinomyces spp.). Furthermore, salivary $\alpha$-amylase is also included into pellicle, which can also bind Gtfs. (2) Surface-adsorbed GtfB and GtfC rapidly utilize dietary sucrose to synthesize insoluble and soluble glucans in situ; the soluble glucans formed by GtfD could serve as primers for GtfB enhancing the overall synthesis of exopolysaccharides. Concomitantly, starch is digested by amylase releasing maltose and a myriad of oligosaccharides; they can be incorporated into the polymer molecule through acceptor reactions, particularly by surface-adsorbed GtfB. The Gtfs adsorbed onto enamel and microbial surfaces provide in situ an insoluble matrix for dental plaque. (3) The glucan molecules provide avid binding sites on surfaces for $S$. mutans (and other microorganisms) mediating tight bacterial clustering and adherence to the tooth enamel. Furthermore, Gtf-adsorbed bacteria become de facto glucan producers binding to tooth and microbial surfaces by the same mechanisms. This model could explain the rapid formation and accumulation of highly cohesive-adherent plaque in the presence of sucrose (and possibly starch) even if the number of $S$. mutans is relatively low. After the establishment of a glucan-rich biofilm matrix, ecological pressure (e.g. $\mathrm{pH}$ ) will determine which bacteria may survive and dominate within plaque under frequent sucrose (or other fermentable carbohydrate) exposure.
Furthermore, dietary starches and sucrose in the presence of surface-adsorbed salivary $\alpha$-amylase and Gtfs enhance the formation of highly insoluble and structurally distinctive 3-dimensional matrix, increasing the accumulation of highly cohesive and adherent biofilms by S. mutans [Duarte et al., 2008; Klein et al., 2009, 2010; Xiao and Koo, 2010]. The sucrose-starch combination also induced complex remodeling of $S$. mutans transcriptome in response to this host-pathogen-diet interaction occurring in situ. The expression of $g t f B$, and several genes involved in carbohydrate uptake and glycogen metabolism were upregulated, which could modulate the dynamics of biofilm development and pathogenicity [Klein et al., 2009, 2010]. The observations reported here may offer an explanation for the phenomenon that combinations of starch and sucrose are more cariogenic than either alone in animal [Bowen et al., 1980; Firestone et al., 1982] and in situ [Ribeiro et al., 2005] models. 
Sparse attention has been devoted to determining the branch structure of polysaccharides found in dental plaque. Earlier examination of pooled plaque samples [Hotz et al., 1972; Emilson et al., 1984] revealed that 18\% of plaque is comprised of carbohydrate, the majority of which is water insoluble. Smith degradation showed that $\alpha-1,3$ or $\alpha-1,3 / 6$ are major linkages of the glucan polymer in plaque; some $\alpha-1,6$-linkage was also detected with smaller amounts of $\alpha-1,4$-linkages (see role of starch). These observations were in marked contrast to earlier reports which claimed that the dominant polysaccharide in plaque was dextran (with predominantly $\alpha$-1,6-linked glucose) which is usually highly soluble [Gibbons and Banghart, 1967].

The structure of the polysaccharide in plaque matrix will also be influenced by the duration since the last ingestion of sucrose and starch. Up to $50 \%$ of polysaccharide in plaque is metabolized over $4 \mathrm{~h}$ at room temperature probably as a result of soluble glucan being digested to glucose and oligosaccharides which are metabolized by bacteria [Critchley et al., 1967; Critchley, 1969; Walker et al., 1981]. Mutanase and dextranase within plaque have the potential to influence the synthesis and structure of glucans. Therefore, a dynamic interaction of the enzymes responsible for glucan synthesis on the one hand with those cleaving the glucosidic linkages (mutanase and dextranase) could be occurring concomitantly in the plaque matrix [Walker et al., 1981; Burne et al., 1986]. It is highly probable that the structure of glucans within plaque matrix undergoes constant change with elevated levels of insoluble polysaccharide in mature plaque [Emilson et al., 1984]. This hypothesis is strongly supported by the observations of Hayacibara et al. [2004], who showed that incorporating dextranase and/or mutanase during the synthesis of glucan by GtfB, C or D in vitro had a profound effect on the amount of glucan formed, its structural properties and bacterial binding sites. Clearly the matrix of plaque is certainly neither static nor homogeneous, but rather undergoing constant restructuring, which can dramatically influence the pathogenicity of this biofilm.

\section{Gtf Expression}

S. mutans harbors 3 distinct $g t f$ genes expressing Gtf activity [Kuramitsu, 1993]. The $g t f B(4.4 \mathrm{kbp})$ and $g t f C$ (4.3 kbp) genes are in an operon-like arrangement and encode GtfB and GtfC enzymes, whereas $g t f D$ gene (5.3 $\mathrm{kbp}$ ), which is not linked to the gtfBC locus, encodes GtfD enzyme. Overall, GtfB and GtfC are highly homologous sharing about $75 \%$ amino acid sequence identity,
GtfD a little less so with approximately $50 \%$ identity to $\mathrm{GtfB}$ and GtfC. The coding sequences of $g t f B$ and $g t f C$ are only 198 bp apart, and can be cotranscribed and be subjected to the same regulatory mechanisms [Ueda et al., 1988; Hudson and Curtiss, 1990; Wexler et al., 1993; Yoshida and Kuramitsu, 2002]. However, it is unclear whether $g t f B$ and $g t f C$ have either a common or an independent promoter. Results from some studies indicate that there is a common promoter upstream of $g t f B$, which creates a polycistronic message that includes a $g t f C$ coding sequence [Ueda et al., 1988; Hudson and Curtiss, 1990; Wexler et al., 1993; Yoshida and Kuramitsu, 2002], whereas others show a potential independent promoter in the intergenic space [Smorawinska and Kuramitsu, 1995; Fujiwara et al., 1998; Goodman and Gao, 2000]. Nevertheless, the $g t f B$ and $g t f C$ promoters appear to be coordinately expressed [Goodman and Gao, 2000]. On the other hand, $g t f D$ gene is located upstream of $g t f B C$ loci, presents an independent promoter and may be regulated in a manner opposite that of $g t f B$ and $g t f C$ [Wexler et al., 1993; Fujiwara et al., 1998].

There are several factors that can influence the $g t f$ gene transcription, translation and secretion, such as carbohydrate availability/source, environmental $\mathrm{pH}$ and growth rate or phase [Wexler et al., 1993; Goodman and Gao, 2000; Li and Burne, 2001; Fujiwara et al., 2002; Abranches et al., 2003; Browngardt et al., 2004; Chen et al., 2006; Shemesh et al., 2006, 2007; Klein et al., 2009]. For example, lowering of the $\mathrm{pH}$ following addition of carbohydrates, an increase in the availability of metabolizable carbohydrates sensed via the phosphotransferase system, or production of glycolytic intermediates may regulate the expression of $g t f$ genes. The $g t f B C$ genes are induced in response to acidification or in response to the presence of an excess of a metabolizable carbohydrate (glucose or sucrose) [Li and Burne, 2001]. In addition, inactivation of the gene encoding EIIAB ${ }^{\text {man }}$ of the phosphotransferase system of $S$. mutans decreases the gtfBC expression [Abranches et al., 2003]. Results from some studies have shown that sucrose induces the expression of gtfB [Burne et al., 1997; Li and Burne, 2001; Shemesh et al., 2006]. Other investigators reported decreased expression of $g t f B$ and $g t f C$ [Fujiwara et al., 2002]. The transcription and translational expression of gtfD but not $g t f B$ and $g t f C$ appears to be specifically induced by copper ions [Chen et al., 2006]. Few studies evaluated the expression of $g t f$ genes in clinical isolates. Comparison of the $g t f$ genes in clinical isolates revealed that the interstrain difference of $g t f B$ and $g t f D$ was limited, while $g t f C$ showed significant interstrain variations [Fujiwara et al., 
1998]. It was also shown that the transcription levels of $g t f B$ and $g t f C$ (and putative transcriptional response regulators) of several clinical isolates of $S$. mutans (corresponding to distinct genotypes) were growth phase dependent and assumed divergent patterns during specific phases of growth [Stipp et al., 2008]. Recently Klein et al. $[2009,2010]$ noted that sucrose and starch hydrolysates enhanced the expression of $g t f B$ in $S$. mutans which resulted in the formation of elevated amounts of insoluble glucans in biofilms formed in vitro, an observation consistent with previous reports [Vacca-Smith et al., 1996a].

RegM (also known as CcpA), the catabolite-repression regulator in $S$. mutans, appears to be critical for an optimal expression of $g t f B$ and $g t f C$ because inactivation of reg $M$ resulted in dramatic decreases in the levels of expression of the $g t f B C$ promoter [Browngardt et al., 2004]. Recently, LuxS-based signaling was shown to be involved in the formation of $S$. mutans biofilm formation by mediating the expression of $g t f B$ and $g t f C$, but not the $g t f D$ gene [Yoshida et al., 2006]. The expression of $g t f B$ and $g t f C$ of the $S$. mutans luxS mutant was enhanced relative to the parental strain whereas the $g t f D$ expression was unaffected. A VicRK signal transduction system in $S$. $m u$ tans also affects $g t f B C D$ expression [Senadheera et al., 2007]; gtfD expression was reduced in the S. mutans vicK null mutant whereas that of $g t f B$ was enhanced when compared to the parent strain [Senadheera et al., 2007]. In particular, deficiency of the trigger factor RopA in $S$. mutans reduced production of GtfB and GtfD as revealed by Western blotting, but the ropA mutant formed more than $50 \%$ more biofilms than the parental strain when sucrose was provided as the supplemental carbohydrate source [Wen et al., 2005]. Clearly, the mechanisms involved in the regulation of the genes encoding Gtf enzymes appear to be complex and still remain to be fully explored. Nevertheless, it is noteworthy that the expression of Gtfs in S. mutans is greatly enhanced when the organisms are grown within a biofilm [Burne et al., 1997]. Much of the work reported above was conducted in vitro; nevertheless, it is clear that comparable conditions could readily arise in plaque formed in vivo.

\section{Role of Each Gtf in Dental Caries Pathogenesis}

There are well-defined hypotheses for the role of each Gtf in the pathogenesis of dental caries. Because each enzyme has properties in common (e.g. binding to sHA), it is unclear whether all these enzymes are essential for the complete expression of virulence. Using an in vitro model, Ooshima et al. [2001] and Tamesada et al. [2004] showed that the presence of GtfC enhanced the amount of glucan formed. In contrast, van der Ploeg and Guggenheim [2004] and Thurnheer et al. [2003, 2006] claimed that deletion of GtfC from $S$. mutans in their multispecies biofilm model was without effect on the matrix of the biofilm but did affect the physical properties of the glucan, an observation consistent with the demonstrated effects of antibody on the structure of glucan [Wunder and Bowen, 2000; Kopec et al., 2002]. A mutant S. mutans that harbored only GtfC was significantly (76\%) less cariogenic than the parent strain that contained the full complement of $g t f$ genes [Wunder and Bowen, unpubl.]. We suggest that GtfC is adsorbed into pellicle where - when exposed to sucrose - it forms glucan in situ; however; it is clear that GtfB may also bind to sHA but with less avidity. The glucans formed on the surface provide an initial matrix that holds bacterial cells together on the sHA surface [Vacca-Smith and Bowen, 1998, 2000; Koo et al., 2010b].

GtfB in contrast binds to many oral microorganisms and in the presence of sucrose and starch hydrolysates forms an insoluble, structurally rigid and cohesive matrix for plaque biofilm [Koo et al., 2010b]; GtfB appears to be responsible for the development of highly structured microcolonies by $S$. mutans either alone or in the presence of other organisms [Koo et al., 2010b; Xiao and Koo, 2010]. GtfD forms soluble glucans that serve as a primer for $\mathrm{GtfB}$ and also as a reserve polysaccharide that can be metabolized by plaque bacteria [Critchley et al., 1967; Walker et al., 1981]. It is highly likely that other soluble glucans from oral microorganisms could also serve as primers for GtfB [Kuramitsu, 1974; Hamada and Torii, 1980; Koga et al., 1983; Tamesada et al., 2004; Reese and Guggenheim, 2007]. However, the effects of soluble glucan primer on the insoluble glucan synthesis are variable depending on the concentration of the dextrans; glucan synthesis was enhanced by low concentrations (1$5 \mathrm{mg} / \mathrm{ml}$ ) of water-soluble dextrans of various molecular weights, but higher concentrations $(10 \mathrm{mg} / \mathrm{ml})$ inhibited glucan synthesis [Hamada and Torii, 1980]. Therefore, it is tempting to speculate that formation and subsequent structure of glucans are influenced by the availability and the structure of the primer glucan which is usually soluble. The interaction of Gtf enzymes responsible for the synthesis of insoluble and soluble EPS may be critical for the optimal biofilm accumulation by $S$. mutans within a multispecies system [Tamesada et al., 2004; Koo et al., 2010b]. 
Overall, all Gtfs from S. mutans appear to play an important role in the formation of virulent plaque via production of a variety of glucans with distinct function and structure. Our observations support previous findings indicating the critical role of $S$. mutans Gtfs and their products in the pathogenesis of dental caries [Tanzer et al., 1974; Yamashita et al., 1993; Mattos-Granner et al., 2000; Vacca-Smith et al., 2007].

\section{Inhibition of Gtfs}

\section{Synthetic and Natural Inhibitors}

Following recognition of the importance of Gtf in the pathogenesis of dental caries, specific inhibition of Gtfs as a means to prevent plaque-related diseases became attractive. Such a selective approach on a proven virulence property intuitively appears more attractive than using a nonspecific antimicrobial agent. Furthermore, it is critical to note that agents which inhibit Gtf in solution may be without effect when the enzyme is adsorbed to a surface [Vacca-Smith and Bowen, 1996; Wunder and Bowen, 1999; Koo et al., 2002c]. Gtf has at least 2 subsites, glucosyl and fructosyl, that could be targets for inhibitors [Devulapalle and Mooser, 2000]. The site containing 3 aspartic acid residues has been identified as the location for glucose conjugation. $\mathrm{Zn}^{2+}$ has been shown to bind to the fructose site. In addition, the enzyme has several separate glucan-binding sites including one found on a $60-\mathrm{kD}$ domain at the $\mathrm{C}$ terminus [Mooser and Wong, 1988]. Clearly there are additional sites on Gtfs to which potential inhibitors could bind.

Although it is recognized that agents which inhibit enzymes in solution may be without effect when the enzymes are adsorbed to a surface [Scheie and Kjeilen, 1987; Vacca-Smith and Bowen, 1996b; Wunder and Bowen, 1999], in general, it has been observed that inhibitors which bind to an active site in solution have a similar effect when the enzyme is bound to a surface. Examples would include deoxynojirimycin, tris(hydroxymethyl) aminomethane and trichlorogalactosucrose [Devulapalle and Mooser, 1994; Wunder and Bowen, 1999; Wright et al., 2002]. They probably bind to the aspartic acids in the active site and act by blocking the formation of glucose transition molecules.

Results from early work revealed that a diverse range of compounds, such as quaternary ammonium compounds, aliphatic amines and antibodies, were effective in inhibiting to a greater or lesser degree undetermined mixtures of Gtfs in solution [Ciardi et al., 1978]. In addi- tion, many natural agents have been explored for their effect on Gtf activity, such as hops, green tea, traditional medicinal plants and food extracts [Wu-Yuan et al., 1988; Ikeno et al., 1991; Otake et al., 1991; Nakahara et al., 1993; Wolinsky et al., 1996; Tagashira et al., 1997; Osawa et al., 2001; Steinberg et al., 2004; Furiga et al., 2008; Hannig et al., 2008b; Yaegaki et al., 2008]. Carbohydrate fatty esters had no effect on Gtf activity from S. sobrinus despite inhibiting growth of the organisms [Devulapalle et al., 2004]. In contrast, oleanic and oleic acid were efficient inhibitors of Gtf activity in solution [Kozai et al., 1987; Won et al., 2007]; the number of double bonds present along with free carboxyl groups was associated with inhibitory activity. According to Yanagida et al. [2000], the high-molecular-weight plant polyphenols displaying strong anti-Gtf activity have a common structural feature shared with catechin-based oligomeric forms (condensed tannins) and/or gallate ester form compounds (hydrolyzable tannins). However, data from studies using mixtures of Gtfs are difficult to interpret because a specific enzyme might be inhibited and the other enzymes in this mixture enhanced, and furthermore the assays were conducted in solution phase. Several substances, many of which are found in plaque, were identified which enhanced activity, e.g. cardiolipin, putrescine and cadaverine [Ciardi et al., 1978].

A large number of compounds have been examined by our laboratory using individual purified $\mathrm{Gtfs}(\mathrm{B}, \mathrm{C}$ and $\mathrm{D}$ enzymes) both in solution phase and adsorbed to sHA surface, including perborate, sodium, metaperiodate, metal ions and naturally occurring substances [VaccaSmith and Bowen, 1996; Wunder and Bowen, 1999; Koo et al., 2000,2002c]. Among them, metal ions $\mathrm{Fe}^{2+} \mathrm{Zn}^{2+} \mathrm{Cu}^{2+}$ and some oxidizing agents (hypochlorite and rose Bengal) exhibited inhibitory properties, which were usually greater when the enzymes were in the soluble phase [Wunder and Bowen, 1999]. Metal ions probably exert their inhibiting effects through the Fenton reaction where they combine with peroxide to produce hydroxyl radical ions [Devulapalle and Mooser, 2001]. Copper ions have also been shown to depress the expression of $g t f$ genes selectively [Chen et al., 2006].

A range of ingredients commonly found in over-thecounter oral hygiene products have been examined for their effects on the 3 common Gtfs in solution and on a surface [Vacca-Smith and Bowen, 1996]. The activity of GtfB in solution was greatly reduced by many commercially available agents, e.g. cetylpyridinium chloride, alexidine dihydrochloride or triclosan; these same agents had a reduced inhibiting effect on enzyme activity ad- 
sorbed to a surface. Remarkably few agents had any effect on GtfC with the exception of chlorhexidine which reduced the activity of the enzyme in solution by more than $60 \%$. GtfC has many hydrophobic domains particularly at the C terminus [Ueda et al., 1988] and may block access by hydrophilic inhibitors to the active site which may explain its comparative resistance to inhibitory agents. Overall it is apparent that the 3 Gtfs are unequally affected by commercial antiplaque agents [Vacca-Smith and Bowen, 1996; Wunder and Bowen, 1999].

Inhibitory effects of several naturally occurring products such as propolis, plants, cranberry extracts and their constituents have been examined as well [Koo et al., 2000, 2002c, 2006, 2010a, b; Gregoire et al., 2007; Murata et al., 2008]. Many of them display partial inhibition of GtfB and GtfC in solution, but only few are potent inhibitors (>90\% inhibition) and even fewer disrupt the activity of surface-adsorbed enzymes. Aqueous-ethanol extracts of propolis (a resinous substance collected by honeybees from various parts of plants) were particularly effective inhibitors of GtfB and GtfC both in solution and on the surface [Koo et al., 2000]. However, the bioactivity of propolis was variable depending on the geographic origin and the biodiversity of the region of sample collection, which influences the chemical composition of this natural product [Koo et al., 1999, 2000]. Further investigation identified specific low-molecular-weight flavones and flavonols as the primary compounds in propolis responsible for inhibition of Gtf activity [Koo et al., 2002c]. Among them, apigenin (4',5,7-trihydroxyflavone) was a highly effective inhibitor of Gtfs (noncompetitive inhibition) even at micromolar concentrations. The presence of hydroxyl $(\mathrm{OH})$ groups at specific positions and the double bond between $\mathrm{C} 2$ and $\mathrm{C} 3$ in the molecular structure of apigenin may provide a site for nucleophilic addition by side chains of amino acid in Gtfs, which could disrupt the enzymatic activity [Koo et al., 2002b]. It is noteworthy that apigenin also decreased the expression of $g t f B$ and gtfC by planktonic cells and biofilms of $S$. mutans without affecting the bacterial viability [Koo et al., 2006].

Recently, specific high-molecular-weight A-type proanthocyanidin oligomers (dimers to dodecamers) isolated from aqueous extract of cranberry effectively diminished the synthesis of insoluble glucans by surface-adsorbed GtfB [Koo et al., 2010a]. The high-molecularweight polyphenols may have site-specific actions as reported by Matsumoto et al. [2003], who demonstrated that the oolong tea fraction rich in polymeric polyphenols reduced glucan synthesis noncompetitively by targeting the glucan-binding domain of $S$. mutans GtfB and
GtfD in solution phase. The high-molecular-weight polymeric proanthocyanidins consisting exclusively of epicatechin units linked mainly by C- $4 \beta$ and C- 8 bonds were identified as major bioactive agents in cocoa extracts [Osawa et al., 2001]. We found that the presence of A-type double interflavan linkage (which confers structural rigidity to the molecule) and a degree of polymerization ranging from 4 to 12 were considered optimal for effective inhibition of surface-adsorbed enzyme [Koo et al., 2010a]. The actions on Gtfs, especially surface-adsorbed GtfB and GtfC, were found to be one of the major mechanisms by which topical application of A-type proanthocyanidins effectively reduces biofilm accumulation on apatitic surfaces in vitro, and development of dental caries in vivo without displaying microbiocidal activity [Koo et al., 1999, 2002a, b, 2003, 2005, 2010a]. Nevertheless, the exact mechanisms of Gtf inhibition by these bioactive naturally occurring agents remain to be elucidated.

\section{Antibodies}

The possibility of developing an effective vaccine against dental caries has attracted considerable attention over many years [Taubman and Nash, 2006]. Gtfs and fragments of the molecules have been used as an immunogenic agent [Culshaw et al., 2007].

This part of our review focuses on using antibodies that inhibit one or more Gtfs as topical agents. The effects of specific antibodies on the activity of Gtfs and structure of the product glucan have received some attention [Kuramitsu and Ingersoll, 1978b; Kopec et al., 2002]. Interpretation of earlier data is often difficult because in many instances, nondetermined mixtures of Gtfs have been used in the assay or in the preparation of antibodies. Further complications arise from the observation that normal serum harbors substances that enhance Gtf activity [Schachtele and Harlander, 1983]. As a consequence, data on the effect of antibody on Gtf sometimes reported as inhibition is in fact merely a reduction in enhancement; the net effect of the antibody may be enhancement of glucan production [Ciardi et al., 1978; Oho et al., 1999; Kopec et al., 2002]. There are numerous reports on the influence of various antibody preparations on in vitro phenomena such as cell aggregation, glucan synthesis and adhesion to glass surfaces [Olson et al., 1974; Douglas and Russell, 1982; Oho et al., 1999; Kawato et al., 2008]. Few studies appear to have explored the effects of antibodies to specific Gtfs in solution or on a surface, and structure of glucans [Wunder and Bowen, 2000; Kopec et al., 2002]. The structure of GtfB and GtfC glucans formed in the presence of antiserum differed from that of con- 
trols based on the glucan susceptibilities to dextranase and mutanase and linkage analyses.

Antibodies to various preparations of $\mathrm{Gtf}$ have been raised in bovines, hens and used topically to determine their effects on caries in animals and on activity in vitro [Hamada et al., 1991; Krüger et al., 2004]. Topical application of egg-derived antibody that inhibited GtfB (insoluble glucan production) had a dramatic effect on the incidence of caries in rats compared with controls [Hamada et al., 1991; Krüger et al., 2004]. Antibody to the enzyme synthesizing soluble glucan was without effect. These observations are supportive of the importance of GtfB in the pathogenesis of dental caries. Topical application of antibodies to hybrid GtfB and proanthocyanidin (salivabinding protein) reduced the incidence of caries in rats [Mitoma et al., 2002]. It was also noted that antibodies effective against $\mathrm{GtfB}$ and $\mathrm{GtfC}$ in solution had significantly less effect when the enzymes were adsorbed to a surface which suggests that the antibody was not directed against the active site. Antibodies to GtfD were without effect on the activity of GtfB or GtfC [Kuramitsu and Ingersoll, 1978b].

Use of topical antibodies to affect plaque formation has some attraction because the target of action can be highly specific. Furthermore, additional therapeutic agents could be attached to the antibody molecule and thereby lead to the development of a highly selective delivery system.

\section{Conclusions and Future Insights}

Gtfs play an essential role in the expression of virulence by S. mutans in animal models. Free Gtf is incorporated in an active form into tooth pellicle, and the adsorbed enzyme displays enhanced activity over a wide range of $\mathrm{pH}$ values compared with the same enzyme in solution. Exposure of the adsorbed enzyme to sucrose or a combination of sucrose and starch results in formation of glucan in situ which provides binding sites for a diversity of microorganisms. Gtfs readily adsorb, even in the presence of saliva, to a wide range of bacteria, thereby converting them into de facto glucan producers. These biological events (fig. 2) probably explain the images of bacteria observed within plaque surrounded by a polysaccharide matrix. Gene expression of GtfB and GtfC is upregulated when $S$. mutans is grown on a surface and in response to acidification of the environment. Thus, Gtfs can perform even under the most extreme conditions experienced in the mouth.

Biology of Streptococcus mutans-Derived Glucosyltransferases
The structure and 3-dimensional architecture of the polysaccharide matrix probably changes over time as a result of environmental challenges found in the oral cavity, such as the action of mutanase and dextranase found within plaque. Gtf being a primary virulence property of S. mutans appears to offer a major and selective target for chemotherapeutic agents to prevent the formation of cariogenic plaque. A large number of agents have been identified that inhibit Gtfs in solution but have a reduced or no effect on adsorbed enzymes. Metal ions, sugar analogs, lipids, natural products and antibodies have been explored for inhibitory effects.

It is clear that Gtfs acting in concert play a critical role in the formation of plaque and in the pathogenesis of dental caries. It is equally apparent that the behavior of these enzymes in solution does not mirror that observed when the enzyme is adsorbed to a surface. The conformational changes associated with the adsorption of salivary and microbe-derived proteins to surfaces are critical to understanding the initiation and subsequent accumulation of biofilms. In addition, results from such investigations are likely to lead to acquiring agents that have enhanced power to inhibit Gtfs in all phases.

Clearly, the reactions of Gtfs in pellicle and in plaque are diverse and complex and remain a challenging enigma. Exploration of the dynamics of the microenvironments within plaque using in situ models in real time could enhance our understanding of the biological phenomena and physical changes within dental plaque. The results of such investigations may have import well beyond the mouth.

\section{Acknowledgement}

The authors' research in this area was supported by grants from the National Institute for Dental and Craniofacial Research (NIDCR/NIH P01 DE11549 and R21 DE15564, to W.H.B.; R01 DE16139 and DE18023, to H.K.). The authors also thank Dr. Jin Xiao for acquiring and processing the confocal fluorescence images of the biofilms. 


\section{References}

Abranches J, Chen YY, Burne RA: Characterization of Streptococcus mutans strains deficient in EIIAB Man of the sugar phosphotransferase system. Appl Environ Microbiol 2003;69:4760-4769.

-Ambatipudi KS, Hagen FK, Delahunty CM, Han X, Shafi R, Hryhorenko J, Gregoire S, Marquis RE, Melvin JE, Koo H, Yates JR: Human common salivary protein 1 (CSP-1) promotes binding of Streptococcus mutans to experimental salivary pellicle and glucans formed on hydroxyapatite surface. J Proteome Res 2010;9:6605-6614.

-Aoki H, Shiroza T, Hayakawa M, Sato S, Kuramitsu HK: Cloning of a Streptococcus mutans glucosyltransferase gene coding for insoluble glucan synthesis. Infect Immun 1986;53: 587-594.

Armstrong WG: The composition of organic films formed on human teeth. Caries Res 1967;1:89-103.

-Banas JA, Vickerman MM: Glucan-binding proteins of the oral streptococci. Crit Rev Oral Biol Med 2003;14:89-99.

Birked D, Rosell K-G: Structural studies on polysaccharides synthetised from sucrose by soluble enzymes in human dental plaque material. Odont Revy 1975;26:281-290.

Black GV: Gelatine forming micro-organisms. Indep Practitioner 1886;7:546-548.

-Bowen WH, Amsbaugh SM, Monell-Torrens S, Brunelle J, Kuzmiak-Jones H, Cole MF: A method to assess cariogenic potential of foodstuffs. J Am Dent Assoc 1980;100:677681.

- Branda SS, Vik A, Friedman L, Kolter R: Biofilms: the matrix revisited. Trends Microbiol 2005; 13:20-26.

Browngardt CM, Wen ZT, Burne RA: RegM is required for optimal fructosyltransferase and glucosyltransferase gene expression in Streptococcus mutans. FEMS Microbiol Lett 2004;240:75-79.

Burne RA, Chen Y-YM, Penders JEC: Analysis of gene expression in Streptococcus mutans in biofilms in vitro. Adv Dent Res 1997;11:100109

- Burne RA, Rubinfeld B, Bowen WH, Yasbin RE: Tight genetic linkage of a glucosyltransferase and dextranase of Streptococcus mutans GS-5. J Dent Res 1986;65:1392-1401.

-Chaudhuri B, Rojek J, Vickerman MM, Tanzer JM, Scannapieco FA: Interaction of salivary alpha-amylase and amylase-binding-protein A (AbpA) of Streptococcus gordonii with glucosyltransferase of S. gordonii and Streptococcus mutans. BMC Microbiol 2007;7:60.

Chen PM, Chen JY, Chia JS: Differential regulation of Streptococcus mutans gtfBCD genes in response to copper ions. Arch Microbiol 2006;185:127-135.

-Ciardi JE, Bowen WH, Rölla G: The effect of antibacterial compounds on glucosyltransferase activity from Streptococcus mutans. Arch Oral Biol 1978;23:301-305.
Cole MF, Bowen WH: Effect of sodium phytate on the chemical and microbial composition of dental plaque in the monkey (Macaca fascicularis). J Dent Res 1975;54:449-457.

Critchley P: The breakdown of the carbohydrate and protein matrix of dental plaque. Caries Res 1969;3:249-265.

Critchley P, Saxton CA, Kolendo AB: The histology and histochemistry of dental plaque. Caries Res 1968;2:115-129.

Critchley P, Wood JM, Saxton CA, Leach SA: The polymerisation of dietary sugars by dental plaque. Caries Res 1967;1:112-129.

-Cross SE, Kreth J, Zhu L, Sullivan R, Shi W, Qi F, et al: Nanomechanical properties of glucans and associated cell-surface adhesion of Streptococcus mutans probed by atomic force microscopy under in situ conditions. Microbiology 2007;153:3124-3132.

Culshaw S, Larosa K, Tolani H, Han X, Eastcott JW, Smith DJ, Taubman MA: Immunogenic and protective potential of mutans streptococcal glucosyltransferase peptide constructs selected by major histocompatibility complex class II allele binding. Infect Immun 2007;75:915-923.

-Cury JA, Rebelo MA, Del Bel Cury AA, Derbyshire MT, Tabchoury CP: Biochemical composition and cariogenicity of dental plaque formed in the presence of sucrose or glucose and fructose. Caries Res 2000;34: 491-497.

Devulapalle KS, Mooser G: Subsite specificity of the active site of glucosultransferases from Streptococcus sobrinus. J Biol Chem 1994; 269:11967-11971.

Devulapalle KS, Mooser G: Subsite specificity of divalent metal ions to glucosyltransferase. J Craniofac Genet Dev Biol 2000;20:107-108.

Devulapalle KS, Mooser G: Glucosyltransferase inactivation reduces dental caries. J Dent Res 2001;80:466-469.

-Devulapalle KS, Gómez de Segura A, Ferrer M, Alcalde M, Mooser G, Plou FJ: Effect of carbohydrate fatty acid esters on Streptococcus sobrinus and glucosyltransferase activity. Carbohydr Res 2004:339:1029-1034.

-Devulapalle KS, Goodman SD, Gao Q, Hemsley A, Mooser G: Knowledge-based model of a glucosyltransferase from the oral bacterial group of mutans streptococci. Protein Sci 1997;6:2489-2493.

Dibdin GH, Shellis RP: Physical and biochemical studies of Streptococcus mutans sediments suggest new factors linking the cariogenicity of plaque with its extracellular polysaccharide. J Dent Res 1988;67:890-895.

Douglas CW, Russell RR: Effect of specific antisera on adherence properties of the oral bacterium Streptococcus mutans. Arch Oral Biol 1982;27:1039-1045.

Douglas CWI: The binding of human salivary alpha-amylase by oral strains of streptococcal bacteria. Arch Oral Biol 1983;28:567-573.
Douglas CWI, Russell RRB: The adsorption of human salivary components to strains of bacterium Streptococcus mutans. Arch Oral Biol 1984;29:751-757.

Duarte S, Klein MI, Aires CP, Cury JA, Bowen $\mathrm{WH}, \mathrm{Koo} \mathrm{H}$ : Influences of starch and sucrose on Streptococcus mutans biofilms. Oral Microbial Immunol 2008;23:206-212.

Eggen KH, Rölla G: Further studies on the composition of the acquired enamel pellicle. Scand J Dent Res 1983;91:439-446.

Emilson CG, Nilsson B, Bowen WH: Carbohydrate composition of dental plaque from primates with irradiation caries. J Oral Pathol 1984:13:213-220.

-Fears KP, Latour RA: Assessing the influence of adsorbed-state conformation on the bioactivity of adsorbed enzyme layers. Langmuir 2009;25:13926-13933.

- Firestone AR, Schmid R, Mühlemann HR: Cariogenic effects of cooked wheat starch alone or with sucrose and frequency-controlled feedings in rats. Arch Oral Biol 1982;27:759763.

Flemming H-C, Wingender: The biofilm matrix. Nat Rev Microbiol 2010;8:623-633.

Fu DT, Robyt JF: Maltodextrin acceptor reactions of Streptococcus mutans 6715 glucosyltransferases. Carbohydr Res 1991;217:201211.

- Fujiwara T, Hoshino T, Ooshima T, Hamada S: Differential and quantitative analyses of mRNA expression of glucosyltransferases from Streptococcus mutans MT8148. J Dent Res 2002;81:109-113.

- Fujiwara T, Terao Y, Hoshino T, Kawabata S, Ooshima T, Sobue S, Kimura S, Hamada S: Molecular analyses of glucosyltransferase genes among strains of Streptococcus mutans. FEMS Microbiol Lett 1998;161:331336.

Fukui K, Moriyama T: Effect of maltose on glucan synthesis by glucosyltransferases of Streptococcus mutans. Microbiol Immunol 1983;27:917-927.

- Fukushima K, Ikeda T, Kuramitsu HK: Expression of Streptococcus mutans gtf genes in Streptococcus milleri. Infect Immun 1992;60: 2815-2822.

- Furiga A, Dols-Lafargue M, Heyraud A, Chambat G, Lonvaud-Funel A, Badet C: Effect of antiplaque compounds and mouthrinses on the activity of glucosyltransferases from Streptococcus sobrinus and insoluble glucan production. Oral Microbiol Immunol 2008; 23:391-400.

Gibbons RJ: Formation and significance of bacterial polysaccharides in caries etiology. Caries Res 1968;2:164-171.

Gibbons RJ, Banghart SB: Synthesis of extracellular dextran by cariogenic bacteria and its presence in human dental plaque. Arch Oral Biol 1967;12:11-23. 
Gibbons RJ, Hay DI: Adsorbed salivary acidic proline-rich proteins contribute to the adhesion of Streptococcus mutans JBP to apatitic surfaces. J Dent Res 1989;68:1303-1307.

-Gibbons RJ, Hay DI, Childs WC 3rd, Davis G: Role of cryptic receptors (cryptitopes) in bacterial adhesion to oral surfaces. Arch Oral Biol 1990;35:1075-1145.

-Goodman SD, Gao Q: Characterization of the gtfB and gtfC promoters from Streptococcus mutans GS-5. Plasmid 2000;43:85-98.

- Gregoire S, Singh AP, Vorsa N, Koo H: Influence of cranberry phenolics on glucan synthesis by glucosyltransferases and Streptococcus mutans acidogenicity. J Appl Microbiol 2007; 103:1960-1968.

-Guggenheim B: Extracellular polysaccharides and microbial plaque. Int Dent J 1970;20: 657-768.

Guggenheim B, Burckhardt JJ: Isolation and properties of a dextranase from Streptococcus mutans OMZ 176. Helv Odontol Acta 1974;18:101-113.

-Hall-Stoodley L, Costerton JW, Stoodley P: Bacterial biofilms: from the natural environment to infectious diseases. Nat Rev Microbiol 2004;2:95-108.

Hamada S, Tai S, Slade HD: Binding of glycosyltransferase and glucan synthesis by Streptococcus mutans and other bacteria. Infect Immun 1978;21:213-220.

-Hamada S, Torii M: Interaction of glucosyltransferase from Streptococcus mutans with various glucans. J Gen Microbiol 1980;116:5159.

-Hamada S, Horikoshi T, Minami T, Kawabata S, Hiraoka J, Fujiwara T, et al: Oral passive immunization against dental caries in rats by use of hen egg yolk antibodies specific for cell-associated glucosyltransferase of Streptococcus mutans. Infect Immun 1991;59: 4161-4167.

-Hanada N, Kuramitsu HK: Isolation and characterization of the gtfC gene, coding for synthesis of both soluble and insoluble glucans. Infect Immun 1988;56:1999-2005.

-Hanada N, Kuramitsu HK: Isolation and characterization of the Streptococcus mutans gtfD gene, coding for primer-dependent soluble glucan synthesis. Infect Immun 1989;57: 2079-2085.

-Hannig C, Hannig M, Attin T: Enzymes in the acquired enamel pellicle. Eur J Oral Sci 2005; 113:2-13.

-Hannig C, Ruggeri A, Al-Khayer B, Schmitz P, Spitzmüller B, Deimling D, et al: Electron microscopic detection and activity of glucosyltransferases $\mathrm{B}, \mathrm{C}$, and $\mathrm{D}$ in the in situ formed pellicle. Arch Oral Biol 2008a;53: 1003-1010.

-Hannig C, Spitzmüller B, Al-Ahmad A, Hannig M: Effects of Cistus-tea on bacterial colonization and enzyme activities of the in situ pellicle. J Dent 2008b;36:540-545.
Hata S, Mayanagi H: Acid diffusion through extracellular polysaccharides produced by various mutants of Streptococcus mutans. Arch Oral Biol 2003;48:431-438.

Hay DI: The adsorption of salivary proteins by apatite and enamel. Arch Oral Biol 1967;12: 937-947.

Hay DI, Gibbons RJ, Spinell DM: Characteristics of some high molecular weight constituents with bacterial aggregating activity from whole saliva and dental plaque. Caries Res 1971;5:111-113.

Hayacibara MF, Koo H, Vacca-Smith AM, Kopec LK, Scott-Anne K, Cury JA, et al: The influence of mutanase and dextranase on the production and structure of glucans synthesized by streptococcal glucosyltransferases. Caries Res 2004;339:2127-2137.

Honda O, Kato C, Kuramitsu HK: Nucleotide sequence of the Streptococcus mutans gtfD gene encoding the glucosyltransferase-S enzyme. J Gen Microbiol 1990;136:2099-2105.

-Hotz P, Guggenheim B, Schmid R: Carbohydrates in pooled dental plaque. Caries Res 1972;6:103-121.

Hudson MC, Curtiss R 3rd: Regulation of expression of Streptococcus mutans genes important to virulence. Infect Immun 1990;58: 464-470.

Ikeno K, Ikeno T, Miyazawa C: Effects of propolis on dental caries in rats. Caries Res 1991; 25:347-351.

Kato C, Kuramitsu HK: Molecular basis for the association of glucosyltransferases with the cell surface of oral streptococci. FEMS Microbiol Lett 1991;63:153-157.

Kawato T, Yamashita Y, Katono T, Kimura A, Maeno M: Effects of antibodies against a fusion protein consisting of parts of cell surface protein antigen and glucosyltransferase of Streptococcus sobrinus on cell adhesion of mutans streptococci. Oral Microbiol Immunol 2008;23:14-20.

Kho HS, Vacca-Smith AM, Koo H, Scott-Anne K, Bowen WH: Interactions of Streptococcus mutans glucosyltransferase B with lysozyme in solution and on the surface of hydroxyapatite. Caries Res 2005;39:411-416.

Klein MI, De Baz L, Agidi S, Lee H, Xie G, Lin AH, Hamaker BR, Lemos JA, Koo H: Dynamics of Streptococcus mutans transcriptome in response to starch and sucrose during biofilm development. PLoS One 2010; 5:e13478.

Klein MI, Duarte S, Xiao J, Mitra S, Foster TH, Koo H: Structural and molecular basis of the role of starch and sucrose in Streptococcus mutans biofilms development. Appl Environ Microbiol 2009;75:837-841.

- Koga T, Sato S, Inoue M, Takeuchi K, Furuta T, Hamada S: Role of primers in glucan synthesis by glucosyltransferases from Streptococcus mutans strain OMZ176. J Gen Microbiol 1983;129:751-754.
Koga T, Toda Y, Moro I, Hamada S: Electron-microscopic observation of adherence of serotype c Streptococcus mutans to the enamel surface due to glucan synthesis. Zentralbl Bakteriol Mikrobiol 1988;269:492-500.

-Koo H, Cury JA, Rosalen PL, Ambrosano GMB, Ikegaki M, Park YK: Effect of a mouthrinse containing selected propolis on 3-day dental plaque accumulation. Caries Res 2002a;37: 445-448.

Koo H, Duarte S, Murata RM, Scott-Anne K, Gregoire S, Watson GE, Singh AP, Vorsa N: Influence of cranberry proanthocyanidins on formation of biofilms by Streptococcus mutans on saliva-coated apatitic surface and on dental caries development in vivo. Caries Res 2010a;44:116-126.

-Koo H, Hayacibara MF, Schobel BD, Cury JA, Rosalen PL, Park YK, Vacca-Smith AM, Bowen WH: Inhibition of Streptococcus mutans biofilm accumulation and polysaccharide production by apigenin and tt-farnesol. J Antimicrob Chemother 2003;52:782-789.

Koo H, Pearson SK, Scott-Anne K, Abranches J, Cury JA, Rosalen PL, Park YK, Marquis RE, Bowen WH: Effects of apigenin and tt-farnesol on glucosyltransferase activity, biofilm viability and caries development in rats. Oral Microbiol Immunol 2002b;17:337-343.

Koo H, Rosalen PL, Cury JA, Park YK, Bowen WH: Effects of compounds found in propolis on Streptococcus mutans growth and on glucosyltransferase activity. Antimicrob Agents Chemother 2002c;46:1302-1309.

-Koo H, Rosalen PL, Cury JA, Park YK, Ikegaki M, Sattler A: Effect of Apis mellifera propolis from two Brazilian regions on caries development in desalivated rats. Caries Res 1999; 33:393-400.

Koo H, Schobel B, Scott-Anne K, Watson G, Bowen WH, Cury JA, Rosalen PL, Park YK: Apigenin and $t t$-farnesol with fluoride effects on S. mutans biofilms and dental caries. J Dent Res 2005;84:1016-1020.

Koo H, Seils J, Abranches J, Burne RA, Bowen WH, Quivey RG Jr: Influence of apigenin on $g t f$ gene expression in Streptococcus mutans UA159. Antimicrob Agents Chemother 2006;50:542-546.

- Koo H, Vacca-Smith AM, Bowen WH, Rosalen PL, Cury JA, Park YK: Effects of Apis mellifera propolis on the activities of streptococcal glucosyltransferases in solution and adsorbed onto saliva-coated hydroxyapatite. Caries Res 2000;34:418-426

Koo H, Xiao J, Klein MI, Jeon JG: Exopolysaccharides produced by Streptococcus mutans glucosyltransferases modulate the establishment of microcolonies within multispecies biofilms. J Bacteriol 2010b;192:3024-3032.

Kopec LK, Vacca-Smith AM, Bowen WH: Structural aspects of glucans formed in solution and on the surface of hydroxyapatite. Glycobiology 1997;7:929-934. 
Kopec LK, Vacca-Smith AM, Wunder D, NgEvans L, Bowen WH: Influence of antibody on the structure of glucans. Caries Res 2002; 36:108-115

- Korpela A, Yu X, Loimaranta V, Lenander-Lumikari M, Vacca-Smith A, Wunder D: Lactoperoxidase inhibits glucosyltransferases from Streptococcus mutans in vitro. Caries Res 2002;36:116-121.

- Kozai K, Miyake Y, Kohda H, Kametaka S, Yamasaki K, Suginaka H: Inhibition of glucosyltransferase from Streptococcus mutans by oleanolic acid and ursolic acid. Caries Res 1987;21:104-108.

Kreth J, Zhu L, Merritt J, Shi W, Qi F: Role of sucrose in the fitness of Streptococcus mutans. Oral Microbiol Immunol 2008;23:213-219.

-Krüger C, Pearson SK, Kodama Y, Vacca-Smith A, Bowen WH: The effects of egg-derived antibodies to glucosyltransferases on dental caries in rats. Caries Res 2004;38:9-14.

Kuramitsu HK: Adherence of Streptococcus mutans to dextran synthesized in the presence of extracellular dextrasucrase. Infect Immun 1974;9:764-765.

Kuramitsu HK: Virulence factors of mutans streptococci: role of molecular genetics. Crit Rev Oral Biol Med 1993;4:159-176.

Kuramitsu HK, Ingersoll L: Interaction of glucosyltransferase with the cell surface of Streptococcus mutans. Infect Immun 1978a;20: 652-659.

Kuramitsu HK, Ingersoll L: Interaction of Streptococcus mutans glucosyltransferases with antibodies. Adv Exp Med Biol 1978b;107: 727-736.

- Kuramitsu HK, Wondrack L, McGuinness M: Interaction of Streptococcus mutans glucosyltransferases with teichoic acids. Infect Immun 1980;29:376-382.

Leach SA, Saxton CA: An electron microscopic study of the acquired pellicle and plaque formed on the enamel of human incisors. Arch Oral Biol 1966;11:1081-1094.

Li Y, Burne RA: Regulation of the $g t f B C$ and $f t f$ genes of Streptococcus mutans in biofilms in response to $\mathrm{pH}$ and carbohydrate. Microbiology 2001;147:2841-2848.

Lis M, Shiroza T, Kuramitsu HK: Role of C-terminal direct repeating units of the Streptococcus mutans glucosyltransferase-S in glucan binding. Appl Environ Microbiol 1995; 61:2040-2042.

-Lynch DJ, Fountain TL, Mazurkiewicz JE, Banas JA: Glucan-binding proteins are essential for shaping Streptococcus mutans biofilm architecture. FEMS Microbiol Lett 2007;268:158165 .

Marsh PD, Bradshaw DJ: Dental plaque as a biofilm. J Ind Microbiol 1995;15:169-175.

-Matsumoto M, Hamada S, Ooshima T: Molecular analysis of the inhibitory effects of oolong tea polyphenols on glucan-binding domain of recombinant glucosyltransferases from Streptococcus mutans MT8148. FEMS Microbiol Lett 2003;228:73-80.
Mattos-Graner RO, Smith DJ, King WF, Mayer MP: Water-insoluble glucan synthesis by mutans streptococcal strains correlates with caries incidence in 12- to 30-month-old children. J Dent Res 2000;79:1371-1377.

Mayhall CW, Butler WT: The carbohydrate composition of experimental salivary pellicles. J Oral Pathol 1976;5:358-370.

McCabe RM, Donkersloot JA: Adherence of Veillonella species mediated by extracellular glucosyltransferase from Streptococcus salivarius. Infect Immun 1977;18:726-734.

McCabe MM, Hamelik RM: An enzyme from Streptococcus mutans forms branches on dextran in the absence of sucrose. Biochem Biophys Res Commun 1983;115:287-294.

McDougall WA: Studies on the dental plaque. I. The histology of the dental plaque and its attachment. Aust Dent J 1963;8:261-263.

Melsen B, Kaae O, Rölla G, Fejerskov O, Karring T: Penetration of ions in human dental plaque. Arch Oral Biol 1979;24:75-81.

Melvaer KL, Heigeland K, Rölla G: Some physical and chemical properties of 'soluble' and 'insoluble' polysaccharides produced by strains of Streptococcus mutans and S. sanguis. Caries Res 1972;6:79.

-Melvaer KL, Helgeland K, Rölla G: A charged component in purified polysaccharide preparations from Streptococcus mutans and Streptococcus sanguis. Arch Oral Biol 1974; 19:589-595.

Mitoma M, Oho T, Michibata N, Okano K, Nakano Y, Fukuyama M, et al: Passive immunization with bovine milk containing antibodies to a cell surface protein antigen glucosyltransferase fusion protein protects rats against dental caries. Infect Immun 2002;70 2721-2724.

-Monchois V, Arguello-Morales M, Russell RR: Isolation of an active catalytic core of Streptococcus downei MFe28 GTF-1 glucosyltransferase. J Bacteriol 1999;181:2290-2292.

-Mooser G, Wong C: Isolation of glucan-binding domain of glucosyltransferase (1.6-alphaglucan synthase) from Streptococcus sobrinus. Infect Immun 1988;56:880-884.

-Morris EJ, McBride BC: Adherence of Streptococcus sanguis to saliva-coated hydroxyapatite: evidence for two binding sites. Infect Immun 1984;43:656-663.

-Murata RM, Branco de Almeida LS, Yatsuda R, Dos Santos MH, Nagem TJ, Rosalen PL, Koo $\mathrm{H}$ : Inhibitory effects of 7-epiclusianone on glucan synthesis, acidogenicity and biofilm formation by Streptococcus mutans. FEMS Microbiol Lett 2008;282:174-181.

-Nakahara K, Kawabata S, Ono H, Ogura K, Tanaka T, Ooshima T, et al: Inhibitory effect of oolong tea polyphenols on glycosyltransferases of mutans streptococci. Appl Environ Microbiol 1993;59:968-973.

Newbrun E: Polysaccharide synthesis in plaque. Sp Suppl Microbiology Abstracts 1974;111 655-664.
$>$ Oho T, Shimazaki Y, Mitoma M, Yoshimura M, Yamashita Y, Okano K, Nakano Y, Kawagoe H, Fukuyama M, Fujihara N, Koga T: Bovine milk antibodies against cell surface protein antigen PAc-glucosyltransferase fusion protein suppress cell adhesion and alter glucan synthesis of Streptococcus mutans. J Nutr 1999;129:1836-1841.

Olson GA, Guggenheim B, Small PA Jr: Antibody-mediated inhibition of dextran-sucrose-induced agglutination of Streptococcus mutans. Infect Immun 1974;9:273-278.

Ooshima T, Matsumura M, Hoshino T, Kawabata S, Sobue S, Fujiwara T: Contributions of three glycosyltransferases to sucrose-dependent adherence of Streptococcus mutans. J Dent Res 2001;80:1672-1677.

Dosawa K, Miyazaki K, Shimura S, Okuda J, Matsumoto M, Ooshima T: Identification of cariostatic substances in the cacao bean husk: their anti-glucosyltransferase and antibacterial activities. J Dent Res 2001;80:20002004.

Otake S, Makimura M, Kuroki T, Nishihara Y, Hirasawa M: Anticaries effects of polyphenolic compounds from Japanese green tea. Caries Res 1991;25:438-443.

- Paes Leme AF, Bellato CM, Bedi G, Cury AA, Koo H, Cury JA: Effects of sucrose on the extracellular matrix of plaque-like biofilm formed in vivo, studied by proteomic analysis. Caries Res 2008;42:435-443.

Paes Leme AF, Koo H, Bellato CM, Bedi G, Cury JA: The role of sucrose in cariogenic dental biofilm formation - new insight. J Dent Res 2006;85:878-887.

- Pessan JP, Silva SM, Lauris JR, Sampaio FC, Whitford GM, Buzalaf MA: Fluoride uptake by plaque from water and from dentifrice. J Dent Res 2008;87:461-465.

Reese S, Guggenheim B: A novel TEM contrasting technique for extracellular polysaccharides in in vitro biofilms. Microsc Res Tech 2007;70:816-822.

Ribeiro CC, Tabchoury CP, Del Bel Cury AA, Tenuta LM, Rosalen PL, Cury JA: Effect of starch on the cariogenic potential of sucrose. Br J Nutr 2005;94:44-50.

Rölla G, Ciardi JE, Bowen WH: Identification of IgA, IgG, lysozyme, albumin, alpha-amylase and glucosyltransferase in the protein layer adsorbed to hydroxyapatite from whole saliva. Scand J Dent Res 1983a;91:186-190.

Rölla G, Ciardi JE, Schultz SA: Adsorption of glucosyltransferase to saliva coated hydroxyapatite: possible mechanism for sucrose dependent bacterial colonization of teeth. Scand J Dent Res 1983b;91:112-117.

Rölla G, Oppermann RV, Bowen WH, Ciardi JE, Knox KW: High amounts of lipoteichoic acid in sucrose-induced plaque in vivo. Caries Res 1980;14:235-238.

Russell RR: Glucan-binding proteins of Streptococcus mutans serotype c. J Gen Microbiol 1979;112:197-201. 
Russell RR: The application of molecular genetics to the microbiology of dental caries. Caries Res 1994;28:69-82.

- Russell RR, Shiroza T, Kuramitsu HK, Ferretti JJ: Homology of glucosyltransferase gene and protein sequences from Streptococcus sobrinus and Streptococcus mutans. J Dent Res 1988;67:543-547.

- Saxton CA, Kolendo AB: Light and electron histochemical studies of the degradation of salivary glycoproteins and their contribution in plaque formation. Arch Oral Biol 1967;12: 1541-1559.

Schachtele CG, Harlander SK: Factors capable of modifying glucosyltransferase activities from Streptococcus mutans; in Doyle RJ, Ciardi JE (eds): Glucosyltransferases, Glucans, Sucrose and Dental Caries. Spec Suppl Chemical Senses. Washington, IRL Press, 1983, pp 171-178.

- Scheie AA, Eggen KH, Rölla G: Glucosyltransferase activity in human in vivo formed enamel pellicle and in whole saliva. Scand J Dent Res 1987;95:212-215.

- Scheie AA, Kjeilen JC: Effects of chlorhexidine, $\mathrm{NaF}$ and $\mathrm{SnF}_{2}$ on glucan formation by salivary and culture supernatant GTF adsorbed to hydroxyapatite. Scand J Dent Res 1987;95: 532-535.

- Scheie AA, Rölla G: Cell-free glucosyltransferase in saliva. Caries Res 1986;20:344-348.

Schilling KM, Blitzer MH, Bowen WH: Adherence of Streptococcus mutans to glucans formed in situ in salivary pellicle. J Dent Res 1989;68(spec issue):678-680.

Schilling KM, Bowen WH: The activity of glucosyltransferase adsorbed onto saliva-coated hydroxyapatite. J Dent Res 1988;67:2-8.

- Schilling KM, Bowen WH: Glucans synthesized in situ in experimental salivary pellicle function as specific binding sites for Streptococcus mutans. Infect Immun 1992;60:284-295.

- Senadheera MD, Lee AW, Hung DC, Spatafora GA, Goodman SD, Cvitkovitch DG: The Streptococcus mutans vicX gene product modulates $\mathrm{gtfB} / \mathrm{C}$ expression, biofilm formation, genetic competence, and oxidative stress tolerance. J Bacteriol 2007;189:14511458 .

-Shemesh M, Tam A, Feldman M, Steinberg D: Differential expression profiles of Streptococcus mutans ftf, gtf and vicR genes in the presence of dietary carbohydrates at early and late exponential growth phases. Carbohydr Res 2006;341:2090-2097.

- Shemesh M, Tam A, Steinberg D: Expression of biofilm-associated genes of Streptococcus mutans in response to glucose and sucrose. J Med Microbiol 2007;56:1528-1535.

-Shiroza T, Ueda S, Kuramitsu HK: Sequence analysis of the $\mathrm{gtfB}$ gene from Streptococcus mutans. J Bacteriol 1987;169:4263-4270.

- Siqueira WL, Zhang W, Helmerhorst EJ, Gygi SP, Oppenheim FG: Identification of protein opponents in in vivo human acquired enamel pellicle using LC-ESI-MS/MS. J Proteome Res 2007;6:2152-2160.
Smorawinska M, Kuramitsu HK: Primer extension analysis of Streptococcus mutans promoter structures. Oral Microbiol Immunol 1995; 10:188-192.

Steinberg D, Beeman D, Bowen WH: Kinetic properties of glucosyltransferase adsorbed onto saliva-coated hydroxyapatite. Artif Cells Blood Substit Immobil Biotechnol 1996;24:553-566.

Steinberg D, Feldman M, Ofek I, Weiss EI: Effect of a high-molecular-weight component of cranberry on constituents of dental biofilm. J Antimicrob Chemother 2004;54:86-89.

-Stipp RN, Gonçalves RB, Höfling JF, Smith DJ, Mattos-Graner RO: Transcriptional analysis of $g t f B, g t f C$, and $g b p B$ and their putative response regulators in several isolates of Streptococcus mutans. Oral Microbiol Immunol 2008;23:466-473.

Tagashira M, Uchiyama K, Yoshimura T, Shirota M, Uemitsu N: Inhibition by hop bract polyphenols of cellular adherence and water-insoluble glucan synthesis of mutans streptococci. Biosci Biotechnol Biochem 1997;61: 332-335.

Tamasada M, Kawabata S, Fujiwara T, Hamada S: Synergistic effects of streptococcal glucosyltransferases on adhesive biofilm formation. J Dent Res 2004;83:874-879.

- Tanzer JM, Freedman ML, Fitzgerald RJ, Larson RH: Diminished virulence of glucan synthesis-defective mutants of Streptococcus mutans. Infect Immun 1974;10:197-203.

- Tatevossian A: Facts and artefacts in research on human dental plaque fluid. J Dent Res 1990; 69:1309-1315.

Taubman MA, Nash DA: The scientific and public-health imperative for a vaccine against dental caries. Nat Rev Immunol 2006;6:555563.

Thurnheer T, Gmur R, Shapiro S, Guggenheim B: Mass transport of macromolecules within an in vitro model of supragingival plaque. Appl Environ Microbiol 2003;69:1702-1709.

- Thurnheer T, van der Ploeg JR, Giertsen E, Guggenheim B: Effect of Streptococcus mutans $g t f C$ deficiency on mixed oral biofilms in vitro. Caries Res 2006;40:163-171.

- Ueda S, Shiroza T, Kuramitsu HK: Sequence analysis of the gtfC gene from Streptococcus mutans GS-5. Gene 1988;69:101-109.

Vacca-Smith AM, Bowen WH: Effect of some antiplaque agents on the activity of glucosyltransferases of Streptococcus mutans adsorbed onto saliva-coated hydroxyapatite and in solution. Biofilms 1, 1996. http:// www.bdt.org.br/bioline/bf.

-Vacca-Smith AM, Bowen WH: Binding properties of streptococal glucosyltransferases for hydroxyapatite, saliva-coated hydroxyapatite, and bacterial surfaces. Arch Oral Biol 1998;43:103-110.

Vacca-Smith AM, Bowen WH: In situ studies of pellicle formation on hydroxyapatite discs. Arch Oral Biol 2000;45:277-291.
-Vacca-Smith AM, Scott-Anne KM, Whelehan MT, Berkowitz RJ, Feng C, Bowen WH: Salivary glucosyltransferase $\mathrm{B}$ as a possible marker for caries activity. Caries Res 2007; 41:445-450.

- Vacca-Smith AM, Venkitaraman AR, Quivey RG Jr, Bowen WH: Interactions of streptococcal glucosyltransferases with alpha-amylase and starch on the surface of saliva-coated hydroxyapatite. Arch Oral Biol 1996a;41: 291-298.

- Vacca-Smith AM, Venkitaraman AR, Schilling KM, Bowen WH: Characterization of glucosyltransferase of human saliva adsorbed onto hydroxyapatite surfaces. Caries Res 1996b;30:354-360.

-Van der Ploeg JR, Guggenheim B: Deletion of gtfC of Streptococcus mutans has no influence on the composition of a mixedspecies in vitro biofilm model of supragingival plaque. Eur J Oral Sci 2004;112:433438.

-Van Hijum SA, Kralj S, Ozimek LK, Dijkhuizen L, van Geel-Schutten IG: Structure-function relationships of glucansucrase and fructansucrase enzymes from lactic acid bacteria. Microbiol Mol Biol Rev 2006;70:157-176.

- Venkitaraman AR, Vacca-Smith AM, Kopec LK, Bowen WH: Characterization of glucosyltransferase B, gtfC, and gtfD in solution and on the surface of hydroxyapatite. J Dent Res 1995; 74:1695-1701.

Vickerman MM, Jones GW: Adhesion of glucosyltransferase phase variants to Streptococcus gordonii bacterium-glucan substrata may involve lipoteichoic acid. Infect Immun 1992;60:4301-4308.

-Vickerman MM, Sulavik MC, Minick PE, Clewell DB: Changes in the carboxyl-terminal repeat region affect extracellular activity and glucan products of Streptococcus gordonii glucosyltransferase. Infect Immun 1996; 64:5117-5128.

Vickerman MM, Wang M, Baker LJ: An amino acid change near the carboxyl terminus of the Streptococcus gordonii regulatory protein Rgg affects its abilities to bind DNA and influence expression of the glucosyltransferase gene gtfG. Microbiology 2003; 149: 399-406.

-Walker GJ, Pulkownik A, Morrey-Jones JG: Metabolism of the polysaccharides of human dental plaque: release of dextranase in batch cultures of Streptococcus mutans. J Gen Microbiol 1981;127:201-208.

-Wen ZT, Suntharaligham P, Cvitkovitch DG, Burne RA: Trigger factor in Streptococcus mutans is involved in stress tolerance, competence development, and biofilm formation. Infect Immun 2005;73:219-225.

-Wexler DL, Hudson MC, Burne RA: Streptococcus mutans fructosyltransferase (ftf) and glucosyltransferase (gtfBC) operon fusion strains in continuous culture. Infect Immun 1993;61:1259-1267. 
-Wilson RF, Ashley FP: Relationships between the biochemical composition of both free smooth surface and approximal plaque and salivary composition and a $24 \mathrm{~h}$ retrospective dietary history of sugar intake in adolescents. Caries Res 1990;24:203-210.

Wolinsky LE, Mania S, Nachnani S, Ling S: The inhibiting effect of aqueous Azadirachta indica (neem) extract upon bacterial properties influencing in vitro plaque formation. J Dent Res 1996;75:816-822.

-Won SR, Hong MJ, Kim YM, Li CY, Kim JW, Rhee HI: Oleic acid: an efficient inhibitor of glucosyltransferase. FEBS Lett 2007;581: 4999-5002.

-Wood JM: The state of hexose sugar in human dental plaque and its metabolism by the plaque bacteria. Arch Oral Biol 1969;14:161168.
Wright WG, Thelwell C, Svensson B, Russell RR: Inhibition of catalytic and glucan-binding activities of a streptococcal GTF forming insoluble glucans. Caries Res 2002;36:353-359.

Wunder D, Bowen WH: Action of agents on glucosyltransferases from Streptococcus mutans in solution and adsorbed to experimental pellicle. Arch Oral Biol 1999;44:203-214.

-Wunder D, Bowen WH: Effects of antibodies to glucosyltransferases on soluble and insolubilized enzymes. Oral Dis 2000;6:289-296.

Wu-Yuan CD, Chen CY, Wu RT: Gallotannins inhibit growth, water-insoluble glucan synthesis, and aggregation of mutans streptococci. J Dent Res 1988;67:51-55.

Xiao J, Koo H: Structural organization and dynamics of exopolysaccharide matrix and microcolonies formation by Streptococcus mutans in biofilms. J Appl Microbiol 2010;108: 2103-2113.

-Yaegaki K, Tanaka T, Sato T, Murata T, Imai T, Tagashira M, et al: Hop polyphenols suppress production of water-insoluble glucan by Streptococcus mutans and dental plaque growth in vivo. J Clin Dent 2008;19:74-78.
Yamashita Y, Bowen WH, Burne RA, Kuramitsu HK: Role of the Streptococcus mutans gtf genes in caries induction in the specificpathogen-free rat model. Infect Immun 1993;61:3811-3817.

Yanagida A, Kanda T, Tanabe M, Matsudaira F, Oliveira Cordeiro JG: Inhibitory effects of apple polyphenols and related compounds on cariogenic factors of mutans streptococci. J Agric Food Chem 2000;48:5666-5671.

Yoshida A, Ansai T, Takehara T, Kuramitsu HK: LuxS-based signaling affects Streptococcus mutans biofilm formation. Appl Environ Microbiol 2006;71:2372-2380.

Yoshida A, Kuramitsu HK: Multiple Streptococcus mutans genes are involved in biofilm. Appl Environ Microbiol 2002;68:6283-6291. 